\title{
Estrutura da assembléia de peixes de uma lagoa marginal desconectada do rio, no submédio Rio São Francisco, Pernambuco
}

\author{
Sandra Cristina Soares da Luz ${ }^{1,4}$, Ana Carla Asfora El-Deir ${ }^{2}$,Elton José de França ${ }^{3} \&$ William Severi ${ }^{1}$ \\ ${ }^{1}$ Laboratório de Ictiologia, Departamento de Pesca e Aqüicultura, \\ Universidade Federal Rural de Pernambuco - UFRPE \\ ${ }^{2}$ Departamento de Biologia, \\ Universidade Federal Rural de Pernambuco - UFRPE \\ Rua Dom Manoel de Medeiros, s/n, Dois Irmãos, CEP 52171-900, Recife, PE, Brasil \\ ${ }^{3}$ Unidade Acadêmica de Serra Talhada, \\ Fazenda do Saco, s/n, CP 063, CEP 56900-000, Serra Talhada, PE, Brasil \\ ${ }^{4}$ Autor para correspondência: Sandra Cristina Soares da Luz, e-mail: sandracluz7@hotmail.com
}

\begin{abstract}
LUZ, S.C.S., EL-DEIR, A.C.A., FRANÇA, E.J. \& SEVERI, W. Fish assemblage structure in a marginal lake disconnected from the submedium São Francisco River, Pernambuco. Biota Neotrop., 9(3): http://www. biotaneotropica.org.br/v9n3/en/abstract?article+bn01809032009.
\end{abstract}

\begin{abstract}
Samplings with various fishing devices were undertaken between March 2007 and February 2008, in the Curralinho lake, a marginal pond located in the submedium São Francisco river, aiming at evaluating the fish fauna composition after its isolation from the river channel and water depletion. A total of 4,638 specimens was collected, with a biomass of 129,782.84 g, distributed in 16 families and 47 species from the Orders Characiformes, Cyprinodontiformes, Siluriformes, Perciformes, Gymnotiformes and Clupeiformes. Characiformes were most abundant and $87.3 \%$ of the specimens were small $(<100 \mathrm{~mm})$ or medium-sized $(<200 \mathrm{~mm})$. Among the species collected, $26.7 \%$ were constant, $35.6 \%$ accessory and $37.8 \%$ accidental. Characidae encompasses most of the species and individuals, followed by Acestrorhynchidae. Moenkhausia costae, Triportheus guentheri, Pygocentrus piraya and Prochilodus argenteus were present in all samples. Invertivores and piscivores dominated quantitatively and their biomass indicate a predominance of predators, with detritivores presenting the second greatest biomass. Resident species prevailed, with few individuals of migratory fish belonging to Anostomidae and Prochilodontidae families and Salminus franciscanus. Fish richness, diversity and equitability were relatively high throughout the period of study. It may be concluded that the Curralinho lake is an important shelter, feeding and resting ground for the ichthyofauna, mainly for forage fish that serve as the basis of the trophic chain and fisheries's sustainability. Therefore, there is an urgent need of environmental policy and management practices development that would preserve habitat integrity and functionability of their role in the conservation of ichthyodiversity of this stretch of the São Francisco basin.
\end{abstract}

Keywords: Curralinho, San Francisco, fish, ichthyodiversity.

LUZ, S.C.S., EL-DEIR, A.C.A., FRANÇA, E.J. \& SEVERI, W. Estrutura da assembléia de peixes de uma lagoa marginal desconectada do rio, no submédio Rio São Francisco, Pernambuco. Biota Neotrop., 9(3): http://www.biotaneotropica.org.br/v9n3/pt/abstract?article+bn01809032009.

Resumo: Foram realizadas coletas utilizando vários apetrechos de pesca, entre os meses de março/07 e fevereiro/08, na lagoa Curralinho, uma lagoa marginal no trecho submédio do rio São Francisco, com o objetivo de avaliar a composição ictiofaunística após seu isolamento da calha principal do rio e deplecionamento de água. Foi coletado um total de 4.638 espécimes, com uma biomassa de 129.782,84 g, distribuídos em 16 famílias e 47 espécies das ordens Characiformes, Cyprinodontiformes, Siluriformes, Perciformes, Gymnotiformes e Clupeiformes. Observou-se que os Characiformes foram os mais abundantes, com $87,3 \%$ dos exemplares de pequeno $(<100 \mathrm{~mm})$ e médio porte $(<200 \mathrm{~mm})$. Dentre as espécies encontradas, 26,7\% são constantes, 35,6\% acessórias e 37,8\% acidentais. Characidae concentra a maioria das espécies e indivíduos, seguida de Acestrorhynchidae. Moenkhausia costae, Triportheus guentheri, Pygocentrus piraya e Prochilodus argenteus apresentaram constância de $100 \%$. Invertívoros e piscívoros dominaram quantitativamente e sua biomassa indica um domínio de predadores, tendo os detritívoros apresentado a segunda maior biomassa. Houve uma predominância de espécies sedentárias, com poucos exemplares de espécies migradoras, das famílias Anostomidae e Prochilodontidae e Salminus franciscanus. A riqueza, diversidade e eqüitabilidade apresentaram-se relativamente altas durante todo o período de estudo. Pode-se concluir que a lagoa Curralinho é um importante ambiente de abrigo, alimentação e descanso para a ictiofauna, mantendo peixes forrageiros que servem de base para a cadeia trófica e a sustentação pesqueira. Em vista disso, faz-se necessário o desenvolvimento de políticas ambientais e práticas de manejo que preservem a integridade desses habitats e a funcionalidade de seu papel na conservação da ictiodiversidade deste trecho da bacia do São Francisco.

Palavras-chave: Curralinho, São Francisco, peixes, ictiodiversidade. 


\section{Introdução}

A bacia hidrográfica do rio São Francisco é a terceira maior em extensão do Brasil, estando totalmente localizada em território brasileiro, correspondendo a $8 \%$ deste. $\mathrm{O}$ rio é perene, apesar de seus afluentes, localizados na região da caatinga, serem intermitentes (Rosa et al. 2003), podendo apresentar vazões torrenciais no período de novembro a março e nulas de abril a outubro (Sato \& Godinho 1999).

Atualmente, apenas o trecho de $1.100 \mathrm{~km}$ entre as barragens de Três Marias e Sobradinho tem corredeiras, com um desnível de apenas $50 \mathrm{~m}$, com menor velocidade e sujeito a grandes cheias. $\mathrm{O}$ trecho submédio estende-se da cidade de Remanso até o reservatório de Paulo Afonso, cortando os estados de Pernambuco e Bahia. A região se caracteriza por uma topografia ondulada, altitude variando de 200 a $800 \mathrm{~m}$, formando vários vales muito abertos (CODEVASF 2008). Estima-se que, abaixo do reservatório de Três Marias, a planície alagada ocupe uma área de $2.000 \mathrm{~km}^{2}$ (Godinho \& Godinho 2003). Durante a estiagem, os canais e áreas alagadas ficam isolados, formando poças e lagoas marginais que se reconectarão na próxima cheia (Pompeu 1997).

Essas áreas são importantes para a comunidade ictíica por servirem de berçário, proteção e abrigo (Welcomme 1979, Agostinho et al. 1993, Vazzoler et al. 1997, Araújo-Lima \& Oliveira 1998, Medeiros \& Maltchik 2001, Zeug et al. 2005) e locais de crescimento e recuperação de adultos (Agostinho et al. 1993), incluindo espécies de piracema (Vazzoler et al. 1997).

O sucesso na composição da assembléia de peixes em planícies inundáveis é determinado pela duração do pulso de inundação, uma vez que sua colonização ocorre durante os períodos de cheia, aumentando a quantidade de alimento e áreas para abrigo. A extinção ocorre durante o período de seca, com o aumento do nível de predação e redução da oferta de alimento, abrigo e dos níveis de oxigênio dissolvido (Halyc \& Balon 1983, Junk et al. 1989).

Estudos sobre assembléia de peixes em planícies alagáveis no Brasil foram realizados, principalmente, no Pantanal (Catella 1992, Súarez et al. 2004, Muniz 2005) e nas bacias dos rios Amazonas (Petrere Jr. 1983, Junk 1985), Mogi-Guaçu (Meschiatti et al. 2000, Esteves et al. 2000, Simabuku 2005) e Paraná (Marques 1993, Agostinho \& Zalewski 1996, Agostinho et al. 2001, Nakatani et al. 2003, Luz et al. 2004), abordando aspectos como reprodução, estrutura, ictioplâncton e alimentação, mostrando a importância desses ambientes como área berçário e de descanso e recuperação para espécies residentes e de piracema, bem como para a produtividade pesqueira.

Acredita-se, que a comunidade de peixes de uma lagoa marginal, cuja ligação com o rio é sazonalmente interrompida, modifique-se à medida que as condições físico-químicas do ambiente são alteradas com a diminuição do nível hidrológico. Em ambientes tropicais, as mudanças térmicas são pouco perceptíveis, existindo maior influência da precipitação e das inundações sazonais (Lowe-McConnell 1987). A resistência da comunidade a estas variações pode ser acompanhada através das variações de densidade, biomassa e participação relativa dos diferentes grupos tróficos (Zeug et al. 2005).

Sato et al. (1987) realizaram um levantamento em 81 lagoas marginais, no alto São Francisco, acima da represa de Três Marias, e observaram que apenas 28 delas eram perenes. Foram registradas 37 espécies de peixes, dentre as quais 10 eram migradores de importância comercial.

No trecho do médio São Francisco, a montante da represa de Sobradinho, foram realizados estudos em três lagoas marginais (Pompeu, 1997; Pompeu e Godinho 2003), tendo sido capturado um total de 50 espécies, sendo sete delas migradoras. Entretanto, inexistem informações sobre a ictiofauna e suas comunidades no trecho do submédio São Francisco compreendido entre os reserva- tórios de Sobradinho e Itaparica, único trecho remanescente livre de reservatórios nesta porção da bacia.

O objetivo deste trabalho foi analisar a composição ictiofaunística de uma lagoa marginal inserida no trecho submédio do Rio São Francisco, a partir da interrupção de sua ligação com a calha principal do rio, e dos efeitos da diminuição do nível da água sobre a riqueza, diversidade, abundância e participação dos diferentes grupos tróficos.

\section{Área de Estudo}

A lagoa Curralinho está situada no município de Santa Maria da Boa Vista (PE) (08 53'02,7' S e 39 54' 13,1” W), na região do trecho submédio do Rio São Francisco, entre a Usina Hidrelétrica (UHE) de Sobradinho e o reservatório de Itaparica (Figura 1).

É uma lagoa marginal, intermitente, formada numa das depressões existentes ao longo da margem esquerda do rio, possivelmente um canal natural ou antigo leito do próprio rio. Possui uma extensão que varia de acordo com a pluviosidade local e a vazão do Rio São Francisco, formando várias sublagoas que podem secar completamente em anos de estiagem prolongada. O compartimento estudado possui superfície média de $1.121 \mathrm{~m}^{2}$. As chuvas em sua bacia de captação também controlam a variação do nível da lagoa, a qual pode conectar-se ao rio São Francisco durante períodos de aumento de sua vazão, controlada pela operação da UHE de Sobradinho.

A área está localizada no semi-árido nordestino, cuja temperatura atmosférica anual média é de $24^{\circ} \mathrm{C}$. A época de chuvas ocorre no verão (novembro a abril, com pluviometria média anual de 600 a $1.400 \mathrm{~mm}$ ) e estiagem no inverno (maio a agosto) (CODEVASF 2001).

A vegetação marginal da lagoa é formada por caatinga, composta principalmente por árvores xerófilas, arbustos espinhosos e cactáceos, de porte baixo e com pouco sombreamento do corpo d'água. Há poucas macrófitas ao longo das margens da lagoa, muitas delas invasoras terrestres (Cyperaceae, Ipomoea carnea, Polygonium ferrugineum), várias fixas (Marsilea sp.), e algumas flutuantes (Salvinia spp.). Quando o nível da lagoa Curralinho começa a baixar, é comum a presença de algas cianofíceas. O fundo é lamoso, com uma grande quantidade de matéria orgânica, que pode chegar a mais de $80 \mathrm{~cm}$ de profundidade em sua porção central (observação pessoal).

\section{Material e Métodos}

\section{Coleta do material}

As coletas de peixes foram realizadas mensalmente, entre março/2007 e fevereiro/2008, utilizando-se uma bateria de redes de espera com malhas de 12, 15, 20, 25, 30, 35, 40 e 50 mm entre nós adjacentes, com uma exposição mínima de 12 horas, no período noturno. Para a complementação do levantamento da ictiofauna, foram utilizados diferentes apetrechos, tais como: rede de arrasto de multifilamento, com $10 \mathrm{~m}$ de comprimento e $2 \mathrm{~m}$ de altura, com malha de $5 \mathrm{~mm}$, empregadas em áreas abertas e sem vegetação; tarrafa de monofilamento com comprimento de $2,5 \mathrm{~m}$ e malha de $20 \mathrm{~mm}$ entre-nós, além de puçás e peneiras.

Os espécimes coletados foram acondicionados em sacos plásticos devidamente etiquetados, fixados em formalina a $4 \%$ e transportados para o laboratório para identificação, com base em literatura especializada (e.g. Britski et al. 1988). O status taxonômico das espécies foi atualizado segundo Reis et al. (2003) e Buckup et al. (2007). No laboratório, os exemplares tiveram seu comprimento padrão $(\mathrm{CP})$ e peso total $(\mathrm{PT})$ determinados. O material testemunho foi depositado na Coleção de Peixes do Laboratório de Ictiologia do DEPAq/UFRPE. 


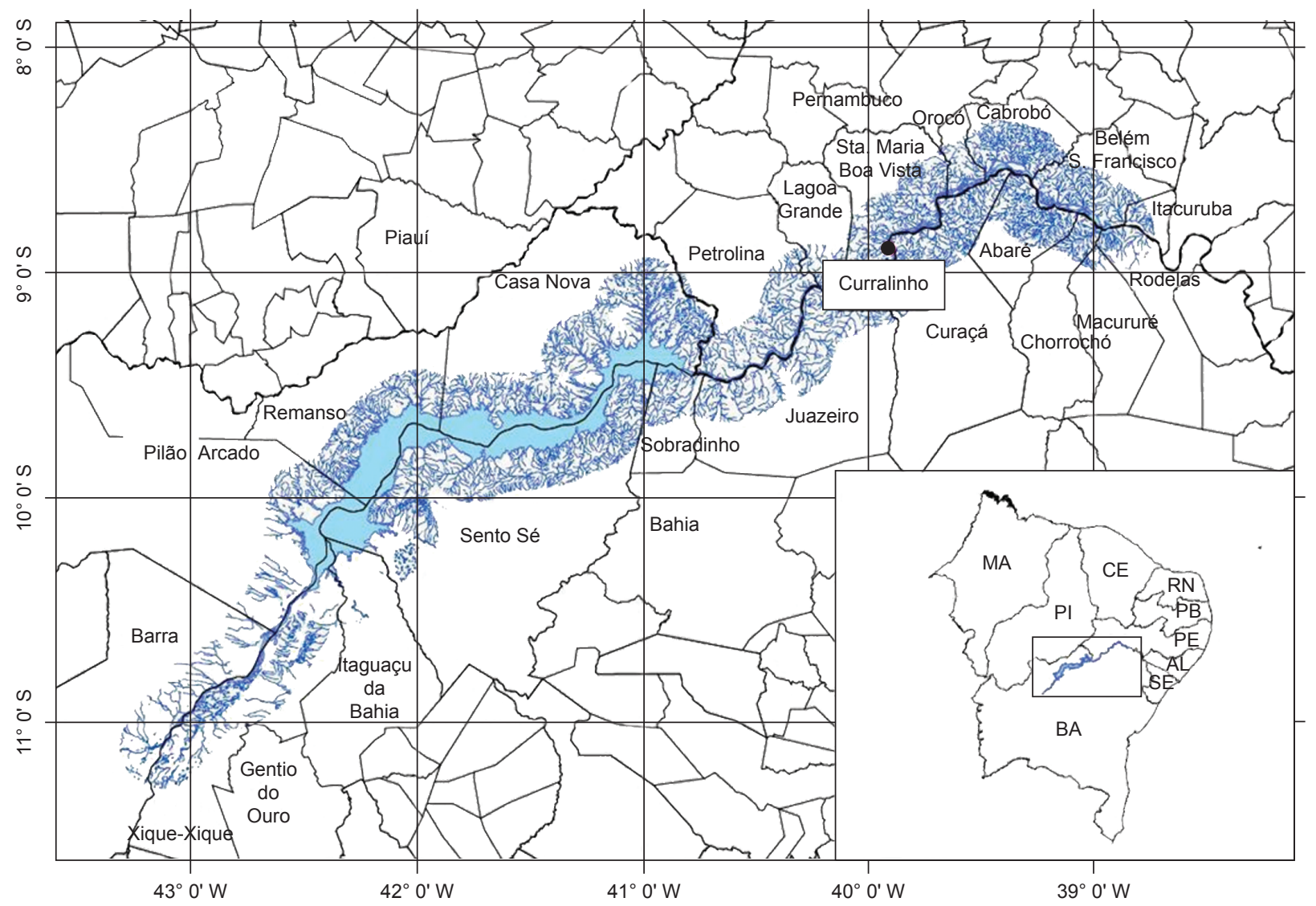

Figura 1. Mapa indicando a localização da lagoa Curralinho (círculo), no município de Santa Maria da Boa Vista, no submédio São Francisco.

Figure 1. Map with location of Curralinho pond (circle), in the municipality of Santa Maria da Boa Vista, submedium São Francisco river.

As variáveis limnológicas temperatura, $\mathrm{pH}$, salinidade, condutividade elétrica e concentração de oxigênio dissolvido foram mensuradas in situ com um analisador multi-parâmetro e a transparência com disco de Secchi.

Dados pluviométricos do município de Santa Maria da Boa Vista (PE) foram obtidos da Agência de Desenvolvimento Agrário (ADAGRO 2008). Valores de vazão defluente da UHE de Sobradinho foram fornecidos pela Divisão de Gestão de Recursos Hídricos (DGRH) da Companhia Hidro Elétrica do São Francisco (CHESF). Foram empregados dados de defluência e precipitação pluviométrica a partir de janeiro/07, de modo a caracterizar a situação imediatamente anterior ao período de estudo.

\section{Análise dos dados}

A normalidade e homocedasticidade dos dados foram analisadas para verificar as diferenças entre meses, aplicando-se teste de contraste de médias e análise de variância, segundo as recomendações de Zar (1996). Foi empregado o teste Kruskall-Wallis, para verificar diferenças significativas $(\mathrm{p} \leq 0,05)$ entre meses.

Foram determinados os índices de eqüitabilidade (Pielou 1966) e diversidade de Brillouin. A similaridade mensal entre as amostras foi expressa em dendrogramas, empregando-se o coeficiente de BrayCurtis, através da associação por médias aritméticas não-ponderadas (UPGMA). A relação entre as características físicas das lagoas, os dados climáticos, limnológicos e ictiológicos foi avaliada através de uma análise de componentes principais (ACP). Para a matriz de similaridade, os dados bióticos foram transformados por raiz quadrada e os dados abióticos estandardizados (logaritmizados). A matriz foi gerada a partir do índice de Bray-Curtis e o método de agrupamento, pela média dos seus valores de similaridade (UPGMA) (Ludwig \& Reynolds 1988).

As espécies foram classificadas segundo sua ocorrência ao longo dos meses, em acidentais ( $\leq 25 \%)$, acessórias ( $>25-\leq 75 \%)$ e constantes ( $>75 \%$ ). Para análise de freqüência e biomassa foram consideradas as espécies que ocorreram em mais de $25 \%$ dos meses e com abundância total maior que $2 \%$. Os indivíduos foram classificados, quanto ao seu tamanho, em pequeno $(\leq 100 \mathrm{~mm})$; médio $(>100-\leq 200 \mathrm{~mm})$ e grande $(>200 \mathrm{~mm})$

As espécies foram classificadas quanto à sua biologia reprodutiva e caráter residente ou migratório, segundo Sato et al. (1987), Pompeu (1997), Sato \& Sampaio (2005) e Pompeu \& Godinho (2006).

A biomassa dos consumidores foi estimada segundo seu enquadramento em quatro grupos tróficos, modificado de Pompeu (1997): 1) carnívoros: engloba os peixes invertívoros (que se alimentam de invertebrados aquáticos e terrestres, principalmente insetos, moluscos e zooplâncton) e piscívoros (que ingerem peixes inteiros e partes, escamas e nadadeiras), 2) onívoros: peixes que se alimentam de vários itens da cadeia trófica, 3) detritívoros: engloba os peixes iliófagos (comedores de lodo e sedimentos), e 4) herbívoros: peixes que se alimentam de algas filamentosas, macrófitas, frutos e vegetais terrestres.

Para efeito de comparação com trabalhos anteriores, foi usada a antiga classificação de "Tetragonopterinae" para espécies da família Characidae encontradas no presente estudo, atualmente enquadradas 
em Incertae Sedis in Characidae (Lima et al. 2003, Buckup et al. 2007).

\section{Resultados}

\section{Dados ambientais}

Na lagoa Curralinho, a precipitação pluviométrica apresentou valor mediano de $32,91 \mathrm{~mm}$ e acumulado de $345 \mathrm{~mm}$ durante todo o período de coleta. Nos meses de janeiro e fevereiro/07, ocorreram as chuvas mais intensas $(81,4$ e $165,1 \mathrm{~mm}$, respectivamente) (Figura 2).

Em fevereiro/07, antes do início das coletas, ocorreu a conexão da lagoa com o Rio São Francisco, extravasando-a por toda a área vizinha, e sua desconexão do rio no fim do mesmo mês. A mais elevada precipitação, neste mês, coincidiu com a maior defluência da UHE de Sobradinho, no período entre janeiro/07 e fevereiro/08 $\left(5.168,47 \mathrm{~m}^{3} / \mathrm{s}\right)$, cuja vazão foi praticamente o dobro daquela liberada em janeiro/07 (Figura 2). Os meses seguintes apresentaram uma redução gradual na defluência, atingindo uma vazão de $756,51 \mathrm{~m}^{3} / \mathrm{s}$, em fevereiro/08.

O nível máximo da água da lagoa foi alcançado em março/07 $(3,50 \mathrm{~m})$ e o mínimo em fevereiro/08 $(0,50 \mathrm{~m})$, devido ao processo de depleção contínua da água (Figura 3a).

Os valores máximos, mínimos e medianos das variáveis ambientais, ao longo de todo o período analisado, constam na Tabela 1, os quais diferiram significativamente $(\mathrm{p}<0,001)$ entre os meses de coleta. Os menores valores de condutividade elétrica $\left(75 \mu \mathrm{S} . \mathrm{cm}^{-1}\right)$ e oxigênio dissolvido $\left(3,82 \mathrm{mg} . \mathrm{L}^{-1}\right)$ foram verificados em março/07 e os maiores, respectivamente, em fevereiro/08 $\left(140 \mu \mathrm{S} . \mathrm{cm}^{-1}\right)$ e agosto/07 (10,26 mg.L $\left.\mathrm{L}^{-1}\right)$ (Figura 3b e 3c).

A temperatura da água da lagoa apresentou uma variação térmica de $10,4{ }^{\circ} \mathrm{C}$ durante todo o período de estudo, com mínimo de $22,9{ }^{\circ} \mathrm{C}$ (agosto/07) e máximo de $33,3{ }^{\circ} \mathrm{C}$ (dezembro/07), observando-se um aumento à medida que o nível da água diminuía a partir de novembro/07 $(1,00 \mathrm{~m})$. As variações da temperatura não tiveram um padrão definido para os períodos de chuva e seca, embora seus maiores valores tenham ocorrido quando a lagoa alcançou o menor nível de água.

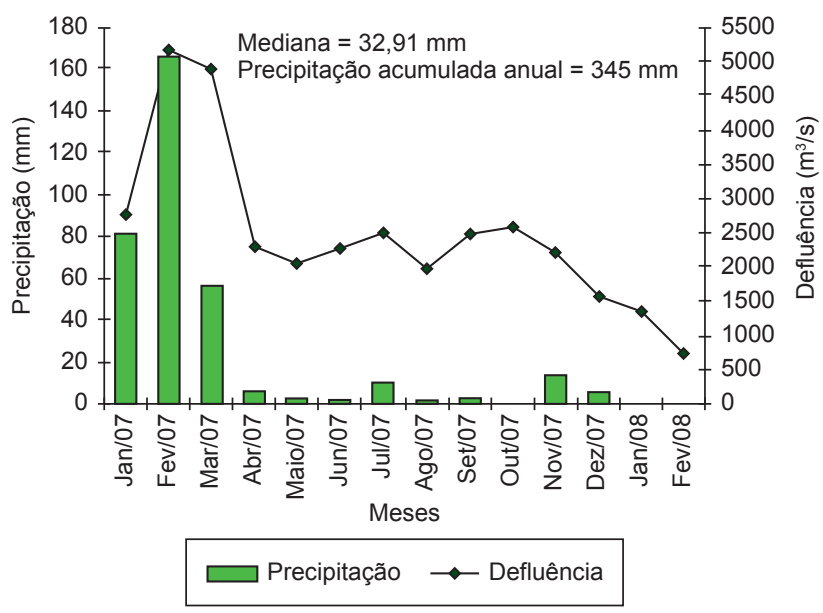

Figura 2. Precipitação mensal acumulada da região de Santa Maria da Boa Vista (PE) e vazão defluente da UHE Sobradinho, durante o período de janeiro/07 a fevereiro/08.

Figure 2. Monthly total rainfall in the region of Santa Maria da Boa Vista $(\mathrm{PE})$ and outflow of Sobradinho power plant, during the period from January 2007 to February 2008.
$\mathrm{O}$ pH da água apresentou valores básicos, cujo menor valor foi registrado em abril/07 $(7,27)$ e o maior em fevereiro/08 $(8,86)$. A transparência apresentou valores entre 0,20 a 1,60 m. Os menores ocorreram a partir de outubro/07, permanecendo constante até o final das coletas,

Tabela 1. Amplitude e mediana dos valores das variáveis ambientais analisadas na lagoa Curralinho, submédio rio São Francisco, no período de março/2007 a fevereiro/2008.

Table 1. Amplitude and median values of environmental variables analyzed in the Curralinho pond, submedium São Francisco river, from March 2007 to February 2008.

\begin{tabular}{lcc}
\hline \multicolumn{1}{c}{ Variáveis ambientais } & Mín.-Máx. & Mediana \\
\hline Condutividade elétrica $\left(\mu \mathrm{S} . \mathrm{cm}^{-1}\right)$ & $75,0-140,0$ & 107,0 \\
Oxigênio dissolvido $\left(\mathrm{mg} . \mathrm{L}^{-1}\right)$ & $3,8-10,2$ & 5,9 \\
$\mathrm{pH}$ & $7,3-8,9$ & 8,12 \\
Profundidade $(\mathrm{m})$ & $0,5-3,5$ & 2,0 \\
Temperatura $\left({ }^{\circ} \mathrm{C}\right)$ & $22,9-33,3$ & 24,9 \\
Transparência $(\mathrm{m})$ & $0,1-1,6$ & 0,45 \\
\hline
\end{tabular}
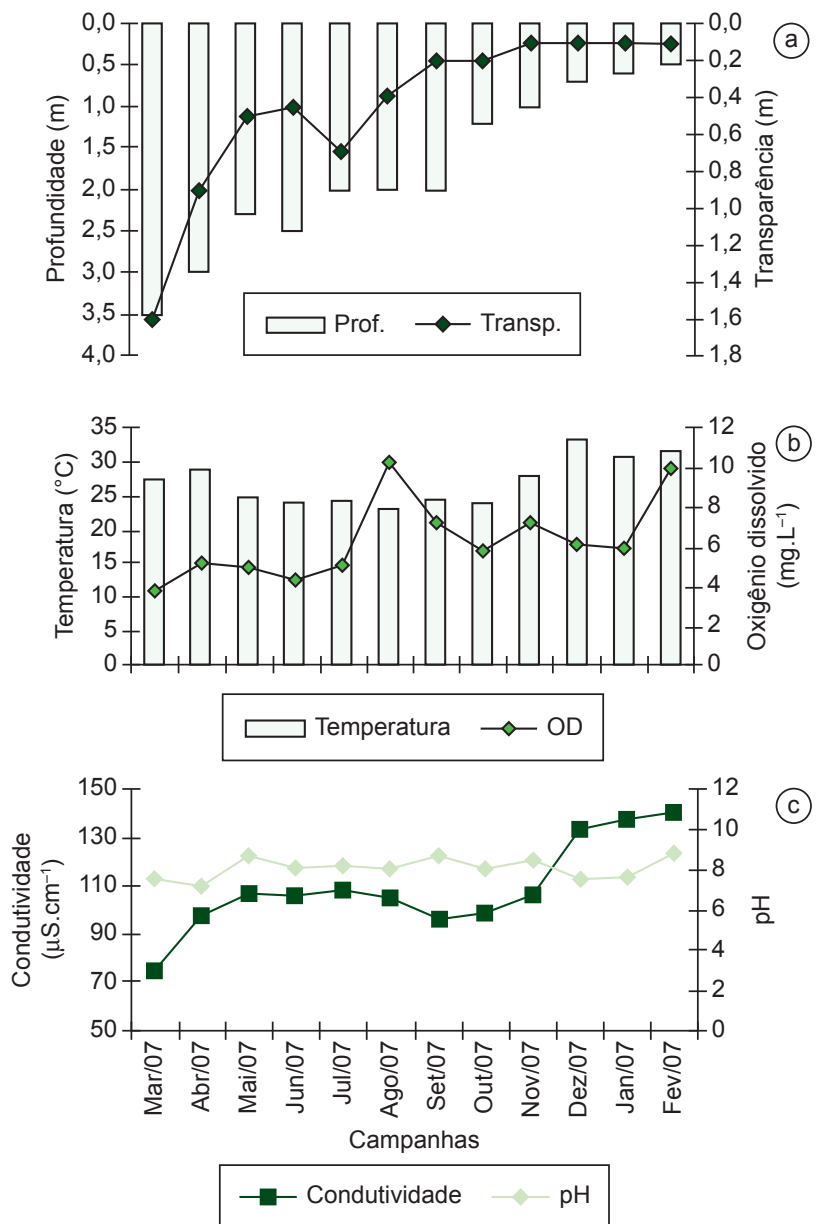

Figura 3. Variação mensal das variáveis ambientais da lagoa Curralinho, durante o período de março/07 a fevereiro/08: a) transparência da água e profundidade da lagoa; b) temperatura e oxigênio dissolvido e c) condutividade elétrica e $\mathrm{pH}$.

Figure 3. Monthly variation of environmental variables of Curralinho pond, during the period from March 2007 to February 2008: a) water transparency and depth; b) temperature and dissolved oxygen, and c) electrical conductivity and $\mathrm{pH}$. 
quando a lagoa Curralinho encontrava-se com os mais baixos níveis da água. A transparência mais elevada foi registrada em março/07 (1,60 m), assim como a maior profundidade da lagoa $(3,50 \mathrm{~m}), \operatorname{logo}$ após sua conexão com o rio, quando as chuvas ainda estavam intensas.

\section{Caracterização da comunidade de peixes}

Durante o período amostrado, foi coletado um total de 4.638 espécimes, 1.667 (123.957,63 g) dos quais foram capturados com rede de emalhar e 2.971 (5.825,21 g) com outros apetrechos (rede de arrasto, tarrafa, puçá e peneiras), o que representa uma biomassa total de $129.782,84$ g. Foram identificadas 47 espécies, pertencentes a seis ordens, distribuídas em 17 famílias (Tabela 2). Characiformes foi a ordem melhor representada, com 91,68\% dos exemplares, seguida de Cyprinodontiformes (6,92\%), Siluriformes (0,52\%), Perciformes $(0,50 \%)$, Gymnotiformes $(0,30 \%)$ e Clupeiformes $(0,09 \%)$.

Tabela 2. Relação de espécies de peixes coletadas na Lagoa Curralinho durante o período de março/07 a fevereiro/08, com respectivos dados biológicos. Classificação taxonômica segundo Reis et al. (2003). Comportamento migratório ( $\mathrm{N}=$ não migrador; $\mathrm{M}=$ migrador $)$ e hábito alimentar $(\mathrm{O}=$ onívoro, $\mathrm{I}=$ invertívoro, $\mathrm{P}=$ piscívoro, $\mathrm{D}=$ detritívoro, $\mathrm{H}=$ herbívoro).

Table 2. List of fish species collected in the Curralinho pond from March 2007 to February 2008, with respective biological data. Taxonomic classification follows Reis et al. (2003). Migratory behavior $(\mathrm{N}=$ non-migratory; $\mathrm{M}=$ migratory) and feeding habit $(\mathrm{O}=$ omnivorous, $\mathrm{I}=$ invertivorous, $\mathrm{P}=$ piscivorous, $\mathrm{D}=$ detritivorous, $\mathrm{H}=$ herbivorous).

\begin{tabular}{|c|c|c|c|c|}
\hline & Taxa & Nome vulgar & $\begin{array}{c}\text { Hábito } \\
\text { alimentar }\end{array}$ & $\begin{array}{l}\text { Comport. } \\
\text { migratório }\end{array}$ \\
\hline \multicolumn{5}{|l|}{ CHARACIFORMES } \\
\hline \multirow[t]{2}{*}{ Acestrorhynchidae } & Acestrorhynchus britskii Menezes, 1969 & Peixe-cachorro & $\mathrm{P}$ & $\mathrm{N}$ \\
\hline & Acestrorhynchus lacustris (Lütken 1875) & Peixe-cachorro & $\mathrm{P}$ & $\mathrm{N}$ \\
\hline \multirow[t]{5}{*}{ Anostomidae } & Leporinus elongatus Valenciennes, 1850 & Piau-verdadeiro & I & M \\
\hline & Leporinus piau Fowler, 1941 & Piau-gordura & $\mathrm{O}$ & M \\
\hline & Leporinus reinhardti Lütken, 1875 & Piau-três-pintas & I & M \\
\hline & Leporinus taeniatus Lütken, 1875 & Piau-jejo & I & M \\
\hline & Schizodon knerii (Steindachner, 1875) & Piau-branco & $\mathrm{H}$ & M \\
\hline \multirow[t]{3}{*}{ Curimatidae } & $\begin{array}{l}\text { Curimatella lepidura } \\
\text { (Eigenmann \& Eigenmann, 1889) }\end{array}$ & Aragu/manjuba/turu & $\mathrm{D}$ & $\mathrm{N}$ \\
\hline & Cyphocharax gilbert (Quoy \& Gaimard, 1824) & Aragu & $\mathrm{D}$ & $\mathrm{N}$ \\
\hline & Steindachnerina elegans (Steindachner, 1875) & Aragu/saguirú & $\mathrm{D}$ & $\mathrm{N}$ \\
\hline Erythrinidae & Hoplias malabaricus (Bloch, 1794) & Traíra & $\mathrm{P}$ & $\mathrm{N}$ \\
\hline Incertae Sedis in & Astyanax fasciatus (Cuvier, 1819) & Piaba-do-rabo-vermelho & $\mathrm{I}$ & $\mathrm{N}$ \\
\hline \multirow[t]{6}{*}{ Characidae } & Astyanax lacustris (Reinhardt, 1874) & Piaba-do-rabo-amarelo & I & $\mathrm{N}$ \\
\hline & Bryconops cf. affinis (Günther, 1864) & Piaba-verde & I & $\mathrm{N}$ \\
\hline & Hemigrammus gracilis (Lütken, 1875) & Piaba & I & $\mathrm{N}$ \\
\hline & Hyphessobrycon santae (Eigenmann, 1907) & Piaba & I & $\mathrm{N}$ \\
\hline & Moenkhausia costae (Steindachner, 1907) & Piabinha & I & $\mathrm{N}$ \\
\hline & $\begin{array}{l}\text { Psellogrammus kennedyi } \\
\text { (Eigenmann, 1903) }\end{array}$ & Piaba & I & $\mathrm{N}$ \\
\hline \multirow[t]{11}{*}{ Characidae } & Salminus franciscanus Lima \& Britski, 2007 & Dourado & $\mathrm{P}$ & M \\
\hline & Serrapinnus heterodon (Eigenmann, 1915) & Piaba & I & $\mathrm{N}$ \\
\hline & Serrapinnus piaba (Lütken, 1875) & Piaba & I & $\mathrm{N}$ \\
\hline & Triportheus guentheri (Garman, 1890) & Piaba-facão & I & $\mathrm{N}$ \\
\hline & Orthospinus franciscoensis (Eigenmann, 1914) & Piabinha & I & $\mathrm{N}$ \\
\hline & Phenacogaster franciscoensis (Eigenmann, 1911) & Piaba & I & $\mathrm{N}$ \\
\hline & Pygocentrus piraya (Cuvier, 1819) & Piranha & $\mathrm{P}$ & $\mathrm{N}$ \\
\hline & Serrasalmus brandtii (Lütken, 1875) & Pirambeba & I & $\mathrm{N}$ \\
\hline & Metynnis spp. Cope, 1878 & Pacuzinho & I & $\mathrm{N}$ \\
\hline & Roeboides xenodon (Reinhardt, 1851) & Piaba & I & $\mathrm{N}$ \\
\hline & Tetragonopterus chalceus Spix \& Agassiz, 1829 & Maria-do-oião & I & $\mathrm{N}$ \\
\hline \multirow[t]{2}{*}{ Prochilodontidae } & Prochilodus argenteus Agassiz, 1829 & Curimatã-pacu & $\mathrm{D}$ & M \\
\hline & Prochilodus costatus Valenciennes, 1850 & Curimatã-pioa & $\mathrm{D}$ & M \\
\hline \multicolumn{5}{|l|}{ CLUPEIFORMES } \\
\hline Engraulidae & Anchoviella vaillanti (Steindachner, 1908) & & I & $\mathrm{N}$ \\
\hline \multicolumn{5}{|c|}{ CYPRINODONTIFORMES } \\
\hline Poeciliidae & Poecilia spp. Bloch \& Schneider, 1801 & & & $\mathrm{~N}$ \\
\hline
\end{tabular}


Tabela 2. Continuação...

\begin{tabular}{|c|c|c|c|c|}
\hline & Taxa & Nome vulgar & $\begin{array}{c}\text { Hábito } \\
\text { alimentar }\end{array}$ & $\begin{array}{l}\text { Comport. } \\
\text { migratório }\end{array}$ \\
\hline \multicolumn{5}{|l|}{ GYMNOTIFORMES } \\
\hline Gymnotidae & Gymnotus carapo Linnaeus, 1758 & Sarapó & I & $\mathrm{N}$ \\
\hline \multirow[t]{2}{*}{ Sternopygidae } & Eigenmannia virescens (Valenciennes, 1842) & Sarapó & I & $\mathrm{N}$ \\
\hline & $\begin{array}{l}\text { Sternopygus macrurus } \\
\text { (Bloch \& Schneider, 1801) }\end{array}$ & Sarapó & & \\
\hline \multicolumn{5}{|l|}{ PERCIFORMES } \\
\hline \multirow[t]{5}{*}{ Cichlidae } & Cichla spp. Bloch \& Schneider, 1801 & Tucunaré & $\mathrm{P}$ & $\mathrm{N}$ \\
\hline & Cichlasoma sanctifranciscense Kullander, 1983 & Cará & I & $\mathrm{N}$ \\
\hline & Crenicichla lepidota Heckel, 1840 & Cará & I & $\mathrm{N}$ \\
\hline & Geophagus brasiliensis (Quoy \& Gaimard, 1824) & Cará & $\mathrm{O}$ & $\mathrm{N}$ \\
\hline & Oreochromis niloticus (Linnaeus, 1758) & Tilápia-do-nilo & $\mathrm{O}$ & $\mathrm{N}$ \\
\hline Sciaenidae & Plagioscion squamosissimus (Heckel, 1840) & Pescada/corvina & $\mathrm{P}$ & $\mathrm{N}$ \\
\hline \multicolumn{5}{|l|}{ SILURIFORMES } \\
\hline Auchenipteridae & Parauchenipterus galeatus (Linnaeus. 1766) & Cangati & I & \\
\hline Callichthyidae & Hoplosternum littorale (Hancock, 1828) & Bufão/tamoatá & $\mathrm{O}$ & \\
\hline \multirow[t]{2}{*}{ Loricariidae } & Hypostomus spp. La Cepède, 1803 & Cari/cascudo & $\mathrm{D}$ & \\
\hline & $\begin{array}{l}\text { Pterygoplichthys etentaculatus } \\
\text { (Spix \& Agassiz, 1829) }\end{array}$ & Cari & $\mathrm{H}$ & \\
\hline Pimelodidae & Pimelodus spp. & Bagre & I & \\
\hline
\end{tabular}

Em termos de número de espécies, $66,7 \%$ delas pertencem a Characiformes, seguida de Perciformes (13,3\%), Siluriformes $(11,1 \%)$ e Gymnotiformes (4,4\%). Clupeiformes e Cyprinodontiformes participaram com apenas um táxon cada, Anchoviella vaillanti e Poecilia spp., respectivamente (Figura 4). Entre os Characiformes, $87,3 \%$ dos exemplares são de pequeno $(<100 \mathrm{~mm})$ e médio porte ( $<200 \mathrm{~mm})$, obtidos através de arrastos, principalmente à medida que a lagoa foi secando (Figura 5).

A família Characidae está representada por 30 espécies, com um percentual de $41,7 \%$ dos indivíduos, seguida de Acestrorhynchidae (2; 30,6\%), Curimatidae $(3 ; 10,7 \%)$, Callichthyidae $(1 ; 4,23 \%)$, Erythrinidae $(1 ; 4,01 \%)$, Anostomidae $(5 ; 3,0 \%)$, Auchenipteridae $(1 ; 2,3 \%)$ e as demais, com percentagens inferiores a $2 \%$.

A. lacustris, $M$. costae e C. lepidura representam, juntas, mais de $50 \%$ do número de indivíduos coletados durante o período de estudo. Juntamente com A. britskii, S. heterodon, $H$. littorale e $H$. malabaricus, intercalaram-se entre as mais abundantes dentre os meses. De acordo com sua frequiência ao longo do deplecionamento da lagoa, entre março e agosto/07, A. lacustris, C. lepidura, A. britskii e $S$. heterodon foram as espécies mais freqüentes. No restante do período (setembro/07 a fevereiro/08), as posições ocupadas pelos diferentes táxons se alteram, observando-se nestes meses a predominância de M. costae, A. lacustris, H. malabaricus e C. lepidura.

No que se refere ao tamanho dos peixes coletados, a maioria dos exemplares $(48,41 \%)$ não ultrapassa $100 \mathrm{~mm}$ de comprimento padrão e 35\% deles encontram-se dentro da faixa de 100 a $150 \mathrm{~mm}$, sendo peixes de pequeno porte ou juvenis, em sua maioria de Characidae (Figura 6). Os maiores valores de $\mathrm{CP}$ foram registrados para Erythrinidae (H. malabaricus), Gymnotidae (G. carapo) e Sternopygidae (E. virescens e S. macrurus).

Os dados de abundância indicam que, dentre as 47 espécies encontradas em Curralinho, 14 (29,79\%) são constantes, 21 (44,68\%) acessórias e $12(25,53 \%)$ acidentais. $M$. costae, $T$. guentheri, P. piraya e $P$. argenteus foram capturadas em todas as coletas, enquanto B. affinis, C. lepidota, G. brasiliensis, L. elongatus, O. niloticus e

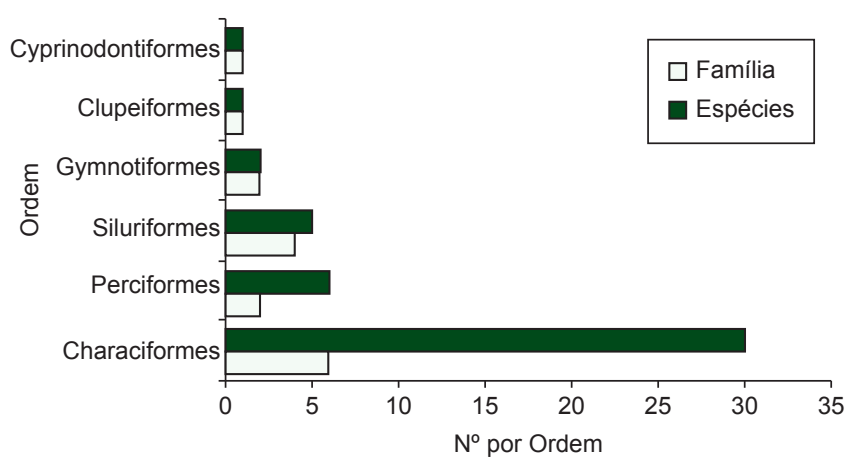

Figura 4. Número de famílias e espécies por Ordem dos peixes coletados na lagoa Curralinho, no período de março/07 a fevereiro/08.

Figure 4. Number of fish families and species per order collected in the Curralinho pond, from March 2007 to February 2008.

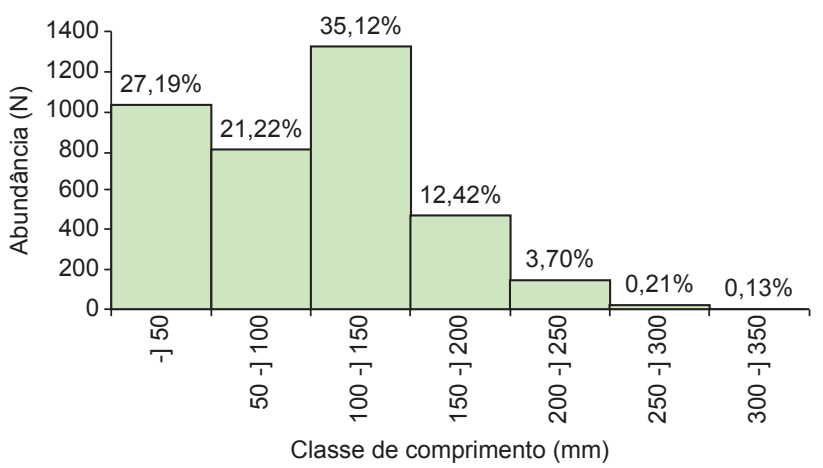

Figura 5. Abundância e participação relativa por classe de comprimento dos peixes coletados na lagoa Curralinho, submédio Rio São Francisco, no período de março/07 a fevereiro/08.

Figure 5. Abundance and relative participation of fish size classes collected in the Curralinho pond, from March 2007 to February 2008. 
P. squamosissimus tiveram apenas um único exemplar coletado em diferentes meses (Tabela 3).

Quanto às espécies introduzidas na bacia, foram capturadas Oreochromis niloticus, Plagioscion squamosissimus, Cichla spp. e Metynnis spp., correspondendo, juntas, a 1,05\% da biomassa de todos os exemplares. Apesar de sua reduzida biomassa em comparação àquela das espécies autóctones (Figura 7), pode-se observar que elas tiveram um aumento ao longo do período estudado, tendo alcançado na fase seca, mais de $25 \%$ de sua biomassa total. Em contrapartida, as espécies autóctones tiveram uma alta da biomassa, porém não ultrapassando $15 \%$ do total.

Considerando o hábito alimentar de todas as espécies que compõem a comunidade de Curralinho (Tabela 2), invertívoros e piscívoros dominaram quantitativamente, com respectivamente 43 e $39 \%$. Contudo, a biomassa dos grupos tróficos indica a predominância de predadores $(66,28 \%)$ no período de estudo (Tabela 3), com exceção dos dois primeiros meses, com reduzida participação de herbívoros $(0,77 \%)$. Os onívoros $(11,77 \%)$ apresentaram a segunda maior biomassa, seguidos dos detritívoros $(11,36 \%)$ e invertívoros $(9,80 \%)$.

As médias do índice de diversidade e eqüitabilidade apresentaram diferença significativa, porém não foi observado um padrão sazonal característico. $\mathrm{O}$ índice mensal de diversidade de Brillouin variou entre 1,126 e 2,398 bits/indivíduos, tendo sido superior a

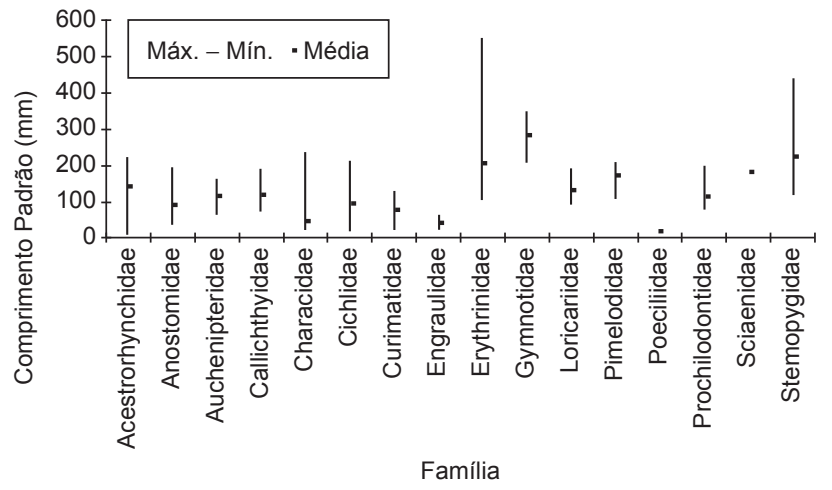

Figura 6. Valores máximo, mínimo e média do comprimento padrão dos indivíduos das diferentes famílias de peixes coletados na lagoa Curralinho, submédio Rio São Francisco, no período de março/07 a fevereiro/08.

Figure 6. Maximum, minimum and average standard lengths of individuals of the different fish families collected in the Curralinho pond, submedium São Francisco River, from March 2007 to February 2008.

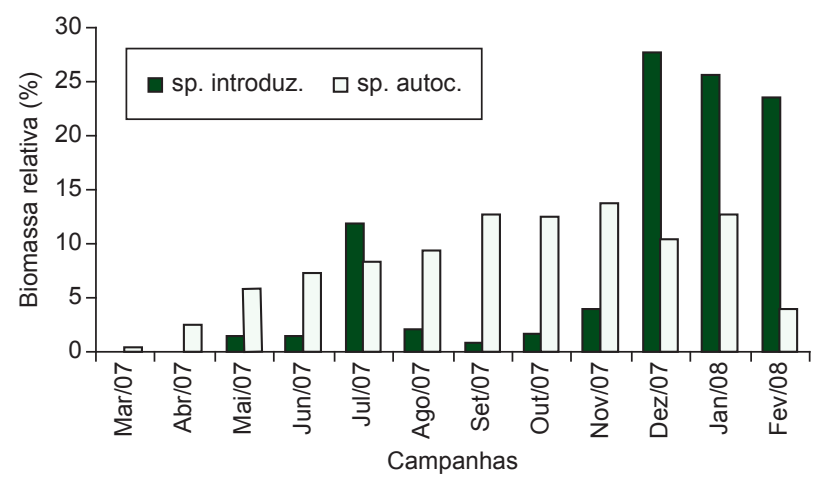

Figura 7. Biomassa relativa (\%) das espécies introduzidas e alóctones coletadas na lagoa Curralinho, no período de Marco/07 a fevereiro/08.

Figure 7. Relative biomass (\%) of introduced and allochthonous fish species collected in the Curralinho pond, from March 2007 to February 2008.

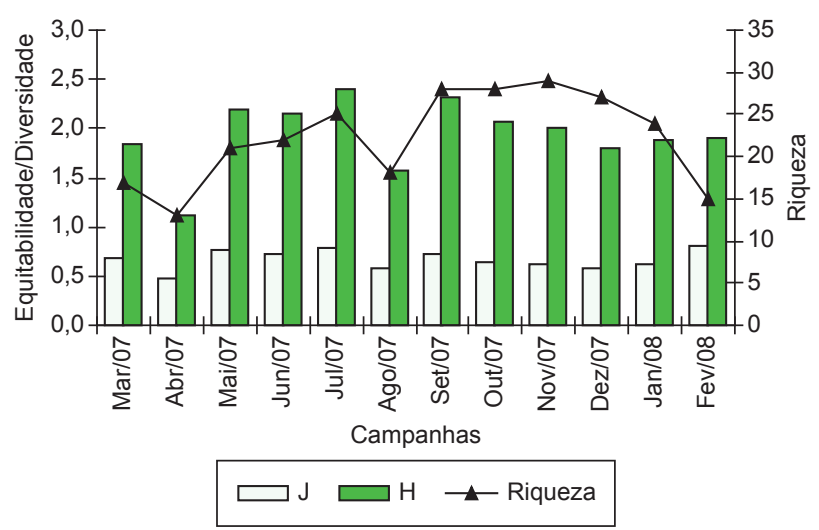

Figura 8. Variação mensal da riqueza de espécies e dos índices de diversidade de Brillouin $(\mathrm{H})$ e de eqüitabilidade (J), da assembléia de peixes da lagoa Curralinho, no período de março/07 a fevereiro/08.

Figure 8. Monthly variation of species richness, and Brillouin diversity $(\mathrm{H})$ and evenness $(\mathrm{J})$ indexes of the fish assemblage of Curralinho pond, from March 2007 to February 2008.

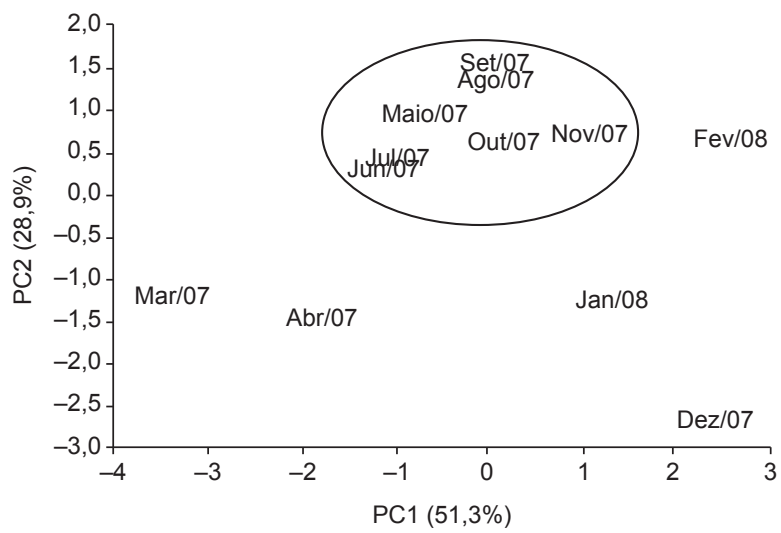

Figura 9. Análise dos componentes principais das variáveis ambientais em relação a diversidade, freqüência, riqueza e biomassa dos peixes da lagoa Curralinho

Figure 9. Principal component analysis of environmental variables in relation to fish diversity, frequency, richness and biomass in the Curralinho pond.

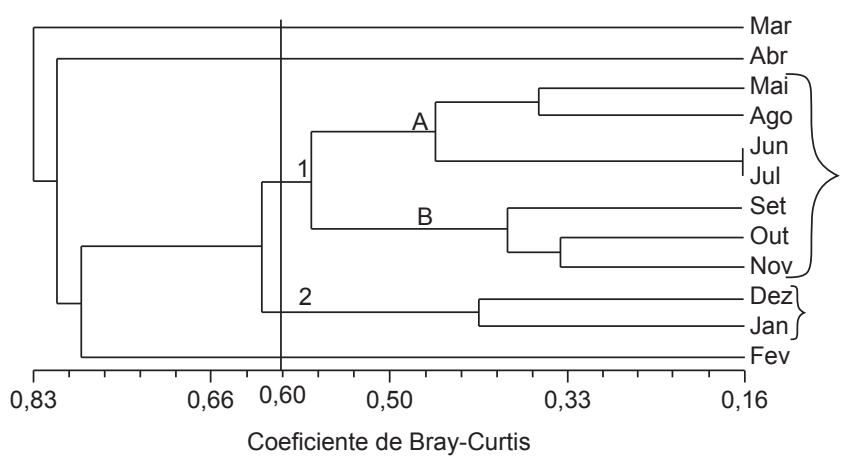

Figura 10. Dendrograma do agrupamento mensal em relação à diversidade, freqüência, riqueza e biomassa da assembléia de peixes da lagoa Curralinho, no submédio rio São Francisco, no período de março/07 a fevereiro/08.

Figure 10. Monthly cluster analysis in relation to fish diversity, frequency, richness and biomass in the Curralinho pond, submedium São Francisco river, from March 2007 to February 2008. 
Tabela 3. Nome abreviado das espécies de peixes, abundância, freqüência relativa (\%), biomassa (g), ocorrência durante os meses de coleta e constância (negrito $=$ espécies constantes; normal $=$ acessórias e sublinhada $=$ acidentais $) . A p=$ Apetrecho com o qual as espécies foram capturadas: $\mathbf{a}=$ apenas nas redes de espera; $\mathbf{b}=$ outros apetrechos; $\mathbf{c}=$ os dois tipos de apetrechos.

Table 3 . Abbreviated name of fish species, abundance, relative frequency $(\%)$, biomass $(\mathrm{g})$, occurrence during sampling months and constancy (in bold = constant; normal $=$ accessory, and underlined $=$ accidental species $) . A p=$ gear used for capture: $\mathbf{a}=$ gillnets only; $\mathbf{b}=$ other gears; $\mathbf{c}=$ both gear types.

\begin{tabular}{|c|c|c|c|c|c|c|c|c|c|c|c|c|c|c|c|c|}
\hline Táxons & Ap. & $\begin{array}{c}\text { Mar } \\
\text { 07 }\end{array}$ & $\begin{array}{c}\text { Abr } \\
\text { 07 }\end{array}$ & $\begin{array}{c}\text { Mai } \\
\text { 07 } \\
\end{array}$ & $\begin{array}{c}\text { Jun } \\
\mathbf{0 7} \\
\end{array}$ & $\begin{array}{c}\text { Jul } \\
\mathbf{0 7} \\
\end{array}$ & $\begin{array}{c}\text { Ago } \\
\text { 07 } \\
\end{array}$ & $\begin{array}{c}\text { Set } \\
07 \\
\end{array}$ & $\begin{array}{c}\text { Out } \\
\text { 07 }\end{array}$ & $\begin{array}{c}\text { Nov } \\
\text { 07 } \\
\end{array}$ & $\begin{array}{c}\text { Dez } \\
07 \\
\end{array}$ & $\begin{array}{c}\text { Jan } \\
\mathbf{0 8} \\
\end{array}$ & $\begin{array}{c}\text { Fev } \\
08 \\
\end{array}$ & $\mathbf{N}$ & $\begin{array}{l}\text { Freq. } \\
\text { Relat. }\end{array}$ & Biomassa \\
\hline M. costae & c & $\mathrm{x}$ & $\mathrm{x}$ & $\mathrm{x}$ & $\mathrm{x}$ & $\mathrm{x}$ & $\mathrm{x}$ & $\mathrm{x}$ & $\mathrm{x}$ & $\mathrm{x}$ & $\mathrm{x}$ & $\mathrm{x}$ & $\mathrm{x}$ & 867 & 18,69 & 487,1 \\
\hline T. guentheri & c & $\mathrm{x}$ & $\mathrm{x}$ & $\mathrm{x}$ & $\mathrm{x}$ & $\mathrm{x}$ & $\mathrm{x}$ & $\mathrm{x}$ & $\mathrm{x}$ & $\mathrm{x}$ & $\mathrm{x}$ & $\mathrm{x}$ & $\mathrm{x}$ & 146 & 3,15 & $1.576,4$ \\
\hline$P$. argenteus & c & $\mathrm{x}$ & $\mathrm{x}$ & $\mathrm{x}$ & $\mathrm{x}$ & $\mathrm{x}$ & $\mathrm{x}$ & $\mathrm{x}$ & $\mathrm{x}$ & $\mathrm{x}$ & $\mathrm{x}$ & $\mathrm{x}$ & $\mathrm{x}$ & 49 & 1,06 & $2.116,8$ \\
\hline$P$. piraya & c & $\mathrm{x}$ & $\mathrm{x}$ & $\mathrm{x}$ & $\mathrm{x}$ & $\mathrm{x}$ & $\mathrm{x}$ & $\mathrm{x}$ & $\mathrm{x}$ & $\mathrm{x}$ & $\mathrm{x}$ & $\mathrm{x}$ & $\mathrm{x}$ & 107 & 2,31 & $4.552,3$ \\
\hline L. piau & c & & $\mathrm{x}$ & $\mathrm{x}$ & $\mathrm{x}$ & $\mathrm{x}$ & $\mathrm{x}$ & $\mathrm{x}$ & $\mathrm{x}$ & $\mathrm{x}$ & $\mathrm{x}$ & $\mathrm{x}$ & $\mathrm{x}$ & 88 & 1,90 & $1.692,2$ \\
\hline O. franciscoensis & c & $\mathrm{x}$ & $\mathrm{x}$ & $\mathrm{x}$ & $\mathrm{x}$ & $\mathrm{x}$ & $\mathrm{x}$ & $\mathrm{x}$ & $\mathrm{x}$ & $\mathrm{x}$ & $\mathrm{x}$ & - & - & 99 & 2,13 & 145,2 \\
\hline S. brandtii & c & $\mathrm{x}$ & $\mathrm{x}$ & $\mathrm{x}$ & $\mathrm{x}$ & $\mathrm{x}$ & $\mathrm{x}$ & $\mathrm{x}$ & $\mathrm{x}$ & $\mathrm{x}$ & - & $\mathrm{x}$ & - & 37 & 0,80 & 280,6 \\
\hline R. xenodon & c & - & $\mathrm{x}$ & $\mathrm{x}$ & $\mathrm{x}$ & $\mathrm{x}$ & $\mathrm{x}$ & $\mathrm{x}$ & $\mathrm{x}$ & $\mathrm{x}$ & $\mathrm{x}$ & $\mathrm{x}$ & - & 93 & 2,01 & $1.055,7$ \\
\hline P. galeatus & $\mathbf{a}$ & - & - & $\mathrm{x}$ & $\mathrm{x}$ & $\mathrm{x}$ & $\mathrm{x}$ & $\mathrm{x}$ & $\mathrm{x}$ & $\mathrm{x}$ & $\mathrm{x}$ & $\mathrm{x}$ & $\mathrm{x}$ & 105 & 2,26 & 5609,5 \\
\hline H. littorale & c & - & - & $\mathrm{x}$ & $\mathrm{x}$ & $\mathrm{x}$ & $\mathrm{x}$ & $\mathrm{x}$ & $\mathrm{x}$ & $\mathrm{x}$ & $\mathrm{x}$ & $\mathrm{x}$ & $\mathrm{x}$ & 196 & 4,23 & $1.3518,1$ \\
\hline H. malabaricus & c & - & - & $\mathrm{x}$ & $\mathrm{x}$ & $\mathrm{x}$ & $\mathrm{x}$ & $\mathrm{x}$ & $\mathrm{x}$ & $\mathrm{x}$ & $\mathrm{x}$ & $\mathrm{x}$ & $\mathrm{x}$ & 186 & 4,01 & $3.3206,9$ \\
\hline Ac. lacustris & c & - & - & $\mathrm{x}$ & $\mathrm{x}$ & $\mathrm{x}$ & $\mathrm{x}$ & $\mathrm{x}$ & $\mathrm{x}$ & $\mathrm{x}$ & $\mathrm{x}$ & $\mathrm{x}$ & $\mathrm{x}$ & 1.116 & 24,06 & $4.0904,3$ \\
\hline Metynnis sp. & $\mathbf{a}$ & - & - & $\mathrm{x}$ & $\mathrm{x}$ & $\mathrm{x}$ & $\mathrm{x}$ & $\mathrm{x}$ & $\mathrm{x}$ & $\mathrm{x}$ & $\mathrm{x}$ & $\mathrm{x}$ & - & 16 & 0,34 & 392,8 \\
\hline C. lepidura & c & - & $\mathrm{x}$ & $\mathrm{x}$ & $\mathrm{x}$ & $\mathrm{x}$ & $\mathrm{x}$ & $\mathrm{x}$ & $\mathrm{x}$ & $\mathrm{x}$ & $\mathrm{x}$ & - & - & 488 & 10,52 & 9984,3 \\
\hline As. lacustris & c & $\mathrm{x}$ & $\mathrm{x}$ & - & - & $\mathrm{x}$ & $\mathrm{x}$ & $\mathrm{x}$ & $\mathrm{x}$ & $\mathrm{x}$ & $\mathrm{x}$ & - & - & 64 & 1,38 & 138,8 \\
\hline T. chalceus & c & $\mathrm{x}$ & - & $\mathrm{x}$ & $\mathrm{x}$ & $\mathrm{x}$ & - & $\mathrm{x}$ & $\mathrm{x}$ & $\mathrm{x}$ & $\mathrm{x}$ & - & - & 95 & 2,05 & 265,3 \\
\hline L. taeniatus & c & $\mathrm{x}$ & $\mathrm{x}$ & - & $\mathrm{x}$ & $\mathrm{x}$ & - & $\mathrm{x}$ & $\mathrm{x}$ & $\mathrm{x}$ & - & $\mathrm{x}$ & - & 22 & 0,47 & 906,4 \\
\hline P. costatus & c & $\mathrm{x}$ & - & $\mathrm{x}$ & $\mathrm{x}$ & $\mathrm{x}$ & $\mathrm{x}$ & - & - & - & $\mathrm{x}$ & $\mathrm{x}$ & $\mathrm{x}$ & 23 & 0,50 & $1.436,1$ \\
\hline S. heterodon & b & $\mathrm{x}$ & - & - & - & - & - & $\mathrm{x}$ & $\mathrm{x}$ & $\mathrm{x}$ & $\mathrm{x}$ & $\mathrm{x}$ & $\mathrm{x}$ & 216 & 4,66 & 24,0 \\
\hline S. knerii & c & - & - & $\mathrm{x}$ & - & $\mathrm{x}$ & $\mathrm{x}$ & $\mathrm{x}$ & $\mathrm{x}$ & - & $\mathrm{x}$ & $\mathrm{x}$ & - & 25 & 0,54 & 288,8 \\
\hline A. britskii & $\mathbf{a}$ & - & $\mathrm{x}$ & $\mathrm{x}$ & $\mathrm{x}$ & $\mathrm{x}$ & $\mathrm{x}$ & $\mathrm{x}$ & $\mathrm{x}$ & - & - & - & - & 277 & 5,97 & $5.098,4$ \\
\hline P. kennedyi & b & $\mathrm{x}$ & - & - & - & $\mathrm{x}$ & - & $\mathrm{x}$ & $\mathrm{x}$ & $\mathrm{x}$ & $\mathrm{x}$ & - & - & 48 & 1,03 & 41,8 \\
\hline S. piaba & b & - & - & - & - & - & - & $\mathrm{x}$ & $\mathrm{x}$ & $\mathrm{x}$ & - & $\mathrm{x}$ & $\mathrm{x}$ & 76 & 1,64 & 17,5 \\
\hline E. virescens & c & - & - & - & $\mathrm{x}$ & - & - & - & $\mathrm{x}$ & $\mathrm{x}$ & $\mathrm{x}$ & - & $\mathrm{x}$ & 11 & 0,24 & 94,1 \\
\hline G. carapo & $\mathbf{a}$ & - & - & - & $\mathrm{x}$ & - & - & - & $\mathrm{x}$ & $\mathrm{x}$ & $\mathrm{x}$ & $\mathrm{x}$ & - & 7 & 0,15 & 634,0 \\
\hline P. etentaculatus & c & - & - & $\mathrm{x}$ & $\mathrm{x}$ & - & - & $\mathrm{x}$ & - & - & $\mathrm{x}$ & - & $\mathrm{x}$ & 7 & 0,15 & 713,0 \\
\hline Poecilia sp. & b & - & - & - & - & - & - & $\mathrm{x}$ & $\mathrm{x}$ & $\mathrm{x}$ & - & - & - & 4 & 0,09 & 0,7 \\
\hline A. fasciatus & b & $\mathrm{x}$ & - & - & - & - & - & $\mathrm{x}$ & $\mathrm{x}$ & $\mathrm{x}$ & - & - & - & 33 & 0,71 & 16,3 \\
\hline A. vaillanti & b & - & - & - & - & - & - & $\mathrm{x}$ & $\mathrm{x}$ & $\mathrm{x}$ & $\mathrm{x}$ & - & - & 24 & 0,52 & 23,4 \\
\hline P. franciscoensis & b & - & - & - & - & - & - & $\mathrm{x}$ & - & - & $\mathrm{x}$ & $\mathrm{x}$ & - & 3 & 0,06 & 0,9 \\
\hline S. elegans & b & - & - & - & - & - & - & - & - & $\mathrm{x}$ & $\mathrm{x}$ & $\mathrm{x}$ & - & 5 & 0,11 & 7,2 \\
\hline L. reinhardti & c & $\mathrm{x}$ & - & - & - & - & - & - & $\mathrm{x}$ & $\mathrm{x}$ & - & - & - & 3 & 0,06 & 67,3 \\
\hline S. macrurus & $\mathbf{a}$ & - & - & $\mathrm{x}$ & - & - & - & - & - & $\mathrm{x}$ & - & $\mathrm{x}$ & - & 5 & 0,11 & 444,3 \\
\hline Cichla sp. & c & - & - & - & - & - & - & - & - & - & $\mathrm{x}$ & $\mathrm{x}$ & $\mathrm{x}$ & 6 & 0,13 & 840,0 \\
\hline Hypostomus sp. & c & - & - & - & - & $\mathrm{x}$ & - & $\mathrm{x}$ & - & - & - & $\mathrm{x}$ & - & 9 & 0,19 & $1.125,0$ \\
\hline H. gracilis & b & - & - & - & - & - & - & $\mathrm{x}$ & - & $\mathrm{x}$ & - & - & - & 2 & 0,04 & 1,0 \\
\hline$\underline{\text { H. santae }}$ & b & $\mathrm{x}$ & - & - & - & $\mathrm{x}$ & - & - & - & - & - & - & - & 6 & 0,13 & 2,5 \\
\hline C. sanctifranciscense & c & - & - & - & - & - & - & - & $\mathrm{x}$ & - & - & $\mathrm{x}$ & - & 4 & 0,09 & 75,5 \\
\hline Pimelodus sp. & $\mathbf{a}$ & - & - & - & $\mathrm{x}$ & $\mathrm{x}$ & - & - & - & - & - & - & - & 4 & 0,09 & 630,0 \\
\hline G. brasiliensis & b & $\mathrm{x}$ & - & - & - & - & - & - & - & - & - & - & - & 1 & 0,02 & 0,8 \\
\hline O. niloticus & b & - & - & - & - & - & - & - & - & - & - & $\mathrm{x}$ & - & 1 & 0,02 & 1,1 \\
\hline C. lepidota & b & - & - & - & - & - & - & - & - & $\mathrm{x}$ & - & - & - & 1 & 0,02 & 3,1 \\
\hline C. gilbert & b & $\mathrm{x}$ & - & - & - & - & - & - & - & - & - & - & - & 3 & 0,06 & 4,9 \\
\hline B. affinis & b & - & $\mathrm{x}$ & - & - & - & - & - & - & - & - & - & - & 1 & 0,02 & 7,3 \\
\hline P. squamosissimus & $\mathbf{a}$ & - & - & - & - & $\mathrm{x}$ & - & - & - & - & - & - & - & 1 & 0,02 & 141,0 \\
\hline L. elongatus & $\mathbf{a}$ & - & - & - & - & - & - & - & - & - & $\mathrm{x}$ & - & - & 1 & 0,02 & 166,0 \\
\hline S. franciscanus & $\mathbf{a}$ & - & - & $\mathrm{x}$ & - & - & - & - & - & - & - & - & - & 6 & 0,13 & 887,0 \\
\hline Especimes danificados & - & $\mathrm{x}$ & - & - & - & $\mathrm{x}$ & - & - & - & - & - & - & - & 24 & 0,52 & 107,7 \\
\hline Frequência absoluta (n) & - & 305 & 258 & 267 & 329 & 405 & 277 & 499 & 821 & 712 & 395 & 300 & 70 & 4.638 & - & - \\
\hline Frequência relativa (\%) & - & 6,58 & 5,56 & 5,76 & 7,09 & 8,73 & 5,97 & 10,7 & 17,7 & 15,35 & 8,52 & 6,47 & 1,51 & - & - & - \\
\hline Riqueza & - & 17 & 13 & 22 & 23 & 26 & 18 & 28 & 29 & 29 & 28 & 24 & 15 & - & - & - \\
\hline
\end{tabular}


1,5 bits/indivíduos em todos os meses, com exceção de abril/07, com o maior índice ocorrendo no mês de julho e o menor em abril. A equiitabilidade variou de 0,467 a 0,805 , tendo sido superior a 0,5 na maioria dos meses, exceto abril/07 (Figura 8), indicando que a distribuição do número de indivíduos por espécie entre os meses foi relativamente homogênea.

O padrão de ocorrência das espécies dentre os meses do ano, com similaridade de 51,3\%, evidenciou a presença de dois grupos distintos. O primeiro, formado por maio a novembro/07 (Figura 9), com dois subgrupos: (A) maio a agosto/07 e (B) setembro a novembro/07. O segundo, com os meses de dezembro/07 e janeiro/08, ambos confirmados pela análise de cluster (Figura 10). Não se agruparam março, abril e fevereiro, provavelmente devido às menores biomassas registradas nestes meses, variando de 0,4 a $4,2 \%$ do peso total.

\section{Discussão}

Os sistemas de rio-planícies alagáveis criam ambientes aquáticos e transicionais que propiciam a manutenção de uma considerável biodiversidade (Thomas et al. 1997), favorecendo o surgimento de áreas berçários. As inundações do rio promovem um aumento do número de habitats, a redistribuição e a dispersão de peixes jovens e adultos, nos lagos e canais principais (Rodríguez \& Lewis 1994). Lagoas marginais que não são inundadas com regularidade deixam de servir como berçários para larvas, afetando o futuro recrutamento de espécies para a população adulta (Agostinho et al. 1993).

Em regiões tropicais, estes sistemas apresentam variações temporais de fatores físicos, químicos e biológicos, determinados, principalmente, pelos pulsos de inundação, como aumento e diminuição da transparência da água, do potencial hidrogeniônico, da condutividade elétrica, do material em suspensão, entre outros (Junk et al. 1989). As chuvas locais e as variações morfométricas da lagoa (área, profundidade e forma) também afetam estes ambientes.

Durante as cheias, as regiões laterais do rio são inundadas formando habitats com características hidrológicas distintas, resultando em novos processos ecológicos e em comunidades diversificadas, tornando estas planícies de inundação locais ideais para a reprodução, alimentação e refúgio. Na estação seca, estes ambientes podem ficar completamente isolados do canal principal, caracterizando-os como ecossistemas bastante peculiares, disponibilizando grande quantidade de alimentos (fitoplâncton, zooplâncton, perifíton, bentos) e abrigos (macrófitas) para os animais aquáticos (Agostinho et al. 2003, Thomaz et al. 2007).

A precipitação pluviométrica na região de Santa Maria da Boa Vista e a vazão da barragem de Sobradinho influenciam diretamente as características físico-químicas da lagoa Curralinho. O padrão de distribuição das chuvas no trecho do médio São Francisco e de ligação e desconexão da lagoa foi similar àquele registrado por Sato et al. (1987), nas lagoas localizadas a montante da represa de Três Marias (MG), e por Pompeu \& Godinho (2003) no trecho médio do rio a montante de Sobradinho.

Numa lagoa marginal no trecho do alto rio São Francisco (MG), Sampaio \& Lopez (2003) também registraram padrão pluviométrico semelhante ao observado no trecho submédio da bacia, onde as maiores precipitações coincidiram com o período de dezembro a fevereiro.

Em relação aos dados ambientais, as temperaturas registradas em Curralinho foram semelhantes às encontradas por Dabés (1995) em cinco lagoas marginais do alto São Francisco, evidenciando uniformidade térmica neste mosaico aquático. Quanto aos valores de oxigênio dissolvido e $\mathrm{pH}$, estes permaneceram elevados durante todo o período de estudo em Curralinho, diferindo dos resultados encontrados por Sampaio \& Lopez (2003) e Dabés (1995), em lago- as marginais do alto São Francisco, onde foram registrados baixos valores de oxigênio dissolvido $\left(3,50 \mathrm{mg} . \mathrm{L}^{-1}\right)$ e $\mathrm{pH}(6,5)$, à medida que as lagoas secavam. Dabés (1995) classificou as águas da lagoa que estudou como: quentes $\left(>28^{\circ} \mathrm{C}\right)$, ligeiramente turvas e ácidas $(>6)$ e com baixa oxigenação $\left(>3,7 \mathrm{mg} \cdot \mathrm{L}^{-1}\right)$. Sendo assim, os valores estáveis de $\mathrm{pH}$ observados em Curralinho devem estar relacionados aos elevados níveis de alcalinidade observados nas águas do submédio rio São Francisco (observação pessoal).

A transparência da água depende da penetração da luz, que é determinada pela cor da água, turbidez e densidade algal (Esteves, 1998). Seus valores na lagoa estudada mostraram correlações positivas com a variação do nível da água, tornando-a mais turva à medida que a lagoa secava. Estes resultados corroboram com os de Sampaio \& Lopez (2000), os quais relacionam os baixos valores de transparência das lagoas marginais à grande quantidade de material em suspensão.

O aumento do material em suspensão em ambientes rasos pode ser causado pela bioturvação, fenômeno ocasionado pelo revolvimento e ressuspensão do sedimento pelos peixes aumentando, assim, a turbidez (Nunes, 2000). Observações similares foram relatadas por Silva \& Esteves (1995) nas baías sob influência dos pulsos de inundação no Pantanal/MT, onde os valores deste parâmetro apresentam um padrão relacionado com a profundidade. Os autores associaram a diminuição da transparência com a ressuspensão do sedimento causada, principalmente, pelo vento e bioturvação devido à atividade de peixes e jacarés. Um aumento na turbidez durante o período de seca também foi observado por Bambi \& Silva (2000) na baía das Pedras, no Pantanal Mato-Grossense (MT).

Em relação à composição da comunidade, foi observada uma nítida predominância de Characiformes. As condições favoráveis de oxigenação, locais de abrigo, de forrageamento por macrófitas e ambiente lêntico pouco profundo oferecem vantagens aos Characiformes de pequeno porte e desfavorecem os Siluriformes, conforme constatado em comunidades ícticas de lagoas marginais do rio Mogi-Guaçu (Ferreira et al. 2000).

Estes padrões são comuns em rios, córregos, lagoas marginais, planícies de inundação, riachos e brejos da região neotropical, conforme observado nos riachos do Parque Estadual do Morro do Diabo (Casatti et al. 2001, Casatti 2005), em lagoas do rio Sorocaba (SP) (Smith \& Barrella 2000), no rio dos Veados (SP) (Castro et al. 2003), em lagoas marginais (Cunico et al. 2002, Sant'Anna et al. 2006) e planícies de inundação do alto rio Paraná (Vazzoler et al. 1997). Para a bacia do rio São Francisco, em lagoas marginais de seu trecho médio (Pompeu 1997, Pompeu \& Godinho 2003) e em brejos de altitude da Paraíba e Pernambuco (Rosa et al. 2003). Também foram registrados em rios costeiros da bacia do Atlântico e outros, como o rio Paraíba do Sul (SP) (Teixeira et al. 2005) e córregos no Alto Tocantins (Miranda \& Mazzoni 2003).

Grande parte dos peixes capturados na lagoa Curralinho é de pequeno e médio porte. Carvalho et al. (2005) encontraram a mesma tendência para o tamanho da comunidade ictiofaunística, para $73 \%$ dos indivíduos capturados numa lagoa marginal do alto Paraná (SP), porém correspondentes a uma biomassa relativa de apenas 1\%. Alguns gêneros, como Serrapinnus, Astyanax e Moenkhausia, pertencentes a Characidae, foram os mais abundantes nas lagoas de planície de inundação do rio Paraná, tanto nas permanentes quanto nas desconectadas (Cunico et al. 2002).

Pompeu (1997) também registrou a abundância das espécies das subfamílias "Tetragonopterinae" e Cheirodontinae nas lagoas marginais do médio São Francisco (MG), principalmente associadas a macrófitas. Characidae foi a família de maior destaque em abundância de espécies e espécimes nas lagoas marginais do rio Mogi-Guaçu (Ferreira et al. 2000), nas lagoas Diogo e Infernão (Galetti et al. 
1990) no mesmo rio e em lagoas da planície de inundação do alto Paraná (Veríssimo 1994; Carvalho et al. 2005). Loureiro-Crippa \& Hahn (2006) ressaltaram que Characidae engloba, em sua maioria, peixes de pequeno porte, com ampla distribuição espacial e ocupando vários níveis da cadeia alimentar.

Em ambientes instáveis, como as lagoas marginais, a colonização ocorre, predominantemente, por espécies r-estrategistas, cujo tamanho é pequeno, de desenvolvimento rápido, reprodução precoce, produtividade elevada e tempo de vida curto (Dajoz 2005). A gênese do local, a influência da sazonalidade nas variáveis limnológicas, a diversidade biológica interdependente, o tipo de fundo, a vegetação e a profundidade são os principais fatores que determinam a estrutura da comunidade nesses ecossistemas (Bonetto et al. 1969).

Dentre as espécies que ocorreram em mais de $75 \%$ da duração do presente estudo, H. malabaricus e L. piau também foram relatadas como espécies presentes em todo o ciclo hidrológico por Medeiros \& Maltchik (2001), estudando a estabilidade das assembléias de peixes em tributários do Rio Taperoá, na região do semi-árido nordestino.

As espécies capturadas na lagoa Curralinho correspondem a 43\% daquelas relatadas por Britski et al. (1988) para a bacia do São Francisco e 64\% das encontradas por Pompeu \& Godinho (2003), em três lagoas marginais do trecho médio do mesmo rio. Contudo, das 50 espécies encontradas por Pompeu e Godinho (2003), 17 não foram coletadas na lagoa Curralinho.

Os trechos de rio a jusante de reservatórios estão sujeitos a modificações do pico de cheias, com atenuação, retardamento ou interrupção dos pulsos de inundação, comprometendo a inundação das planícies alagáveis e alteração do regime hidrológico natural, imposta pela operação da UHE. Esta alteração é considerada uma das principais causas das modificações antropogênicas nesses ambientes (Junk et al. 1989, Sato et al. 2003, Agostinho et al. 2005). Os impactos do reservatório de Três Marias sobre a reprodução de Prochilodus argenteus leva a supor que o barramento das águas afetou as atividades reprodutivas desta espécie na área a jusante da represa, uma vez que o represamento e o controle do fluxo da água modificam as características limnológicas do local (Sato et al. 2003).

As espécies de peixes neotropicais, principalmente em ambientes próximo à linha do Equador, têm seu ciclo de vida fortemente associado à dinâmica do regime hidrológico. A alteração dos pulsos de inundação pode causar uma diminuição na riqueza e densidade ictiofaunística das áreas adjacentes, uma vez que a dinâmica hidrológica define as variações na densidade, diversidade e estrutura trófica da comunidade (Winemiller 1989, Godinho et al. 2007), sendo a sazonalidade e conectividade eventos fundamentais para a integridade biológica das planícies de inundação (Agostinho et al. 2007).

Petry et al. (2003) confirmaram a importância da regularidade das cheias para ambientes lênticos e a comunidade íctica de lagoas marginais do alto Paraná. Por outro lado, a ausência de água durante grande parte do ano e a inconstância de recursos são elementos importantes, que limitam o número de espécies em lagos de regiões semi-áridas (Medeiros \& Maltchik 2001), embora a diversidade e riqueza de peixes sejam altas nesses ambientes, a despeito de sua instabilidade hidrológica.

Cunico et al. (2002) relacionaram o menor período de conexão da calha principal do rio com as áreas de várzea, com a dificuldade das formas jovens adentrarem nestes ambientes para completar seu ciclo de vida. O curto espaço de tempo em que a lagoa Curralinho ficou conectada, com apenas uma inundação durante todo o período de estudo, também pode ter contribuído para a diminuição da riqueza específica, em comparação às lagoas marginais do trecho a montante e jusante da represa de Três Marias (Sato et al. 1987, Pompeu \& Godinho 2003).
A presença de espécies introduzidas em ambientes naturais também representa um fator de degradação faunística (Sato \& Sampaio 2005). Os autores citam a introdução de algumas espécies no alto São Francisco, como Cichla monoculus (tucunaré), Ctenopharyngodon idella (carpa-capim), Cyprinus carpio (carpa comum), Clarias gariepinus (bagre-africano) e Oreochromis niloticus (tilápia-doNilo). Ressaltam, porém, que o número de espécies introduzidas pode ser ainda maior, em decorrência de outras espécies usadas em projetos de pesque-pague e em pisciculturas para a "recuperação da ictiofauna", destinadas à realização de peixamentos, inclusive com espécies exóticas. Paiva et al. (1994) citam que, em dez anos, a tilápia do Nilo (O. niloticus) foi a espécie mais introduzida em dezessete dos grandes reservatórios brasileiros, seguida da pescada do piauí (P. squamisissimus) e do tucunaré (C. ocellaris).

A introdução de peixes causa grandes modificações na composição da ictiofauna (Welcomme 1979), o que foi comprovado por Latini \& Petrere (2004) para a comunidade íctica dos lagos na bacia do rio Doce (MG). Os autores constataram uma redução da riqueza dos peixes nativos, devido à predação e competição pela mesma guilda trófica. Duas características ecológicas podem influenciar nestes resultados, como o cuidado parental e o comportamento predador dos tucunarés, ocasionando um aumento em sua biomassa e diminuição de peixes de pequeno porte e jovens de espécies de maior porte da lagoa.

Espécies introduzidas são comuns nas diversas bacias hidrográficas do Brasil, sendo mais evidentes em reservatórios, devido aos programas de peixamento e ao escape de tanques de piscicultura (Sato \& Sampaio 2005, Agostinho et al. 2007). Existe registro, em trabalhos na bacia do São Francisco para a tilápia, a pescada e o tucunaré (Sato \& Sampaio 2005). Porém, até o presente momento, espécies de Metynnis não haviam sido citadas para a bacia, a despeito de serem comumente capturadas no reservatório de Sobradinho e no complexo de Paulo Afonso (BA). Os exemplares do gênero coletados em Curralinho, provavelmente tratam-se de M. maculatus ou M. lippincottianus, endêmicas da bacia do Amazonas e Paraguai, respectivamente, cujo status taxonômico necessita ser definido.

Agostinho et al. (2007) verificaram a predominância de espécies sedentárias em reservatórios brasileiros, capazes de desenvolver todas as suas atividades vitais em uma área restrita da bacia, sendo poucos os exemplares de espécies migradores das famílias Anostomidae e Prochilodontidae. Dentre as espécies capturadas em Curralinho, sete são migradoras: L. piau, L. reinhardti, L. taeniatus, S. knerii, $S$. franciscanus, $P$. argenteus e $P$. costatus, representando $4,55 \%$ dos peixes capturados e $5,14 \%$ da biomassa. Todos os indivíduos eram jovens, com comprimento padrão inferior a $200 \mathrm{~mm}$. No presente trabalho, Anostomidae obteve a maior freqüência, com 55,38\% dos migradores, enquanto Prochilodontidae apresentou maior biomassa, com $52,09 \%$.

Pompeu (1997) encontrou oito espécies de piracema nas lagoas marginais do médio São Francisco, em sua maioria, jovens, incluindo espécies do gênero Leporinus, sendo que dentre aquelas registradas na lagoa Curralinho, apenas L. piau não foi capturada por esse autor.

Espécies de Curimatidae e Prochilodontidae são comumente encontradas em lagoas marginais, no médio São Francisco (Pompeu \& Godinho 2003, Pompeu \& Godinho 2006), no alto rio Paraná (Cunico et al. 2002, Petry et al 2003, Petry et al. 2004), e no rio Mogi-Guaçu/ SP (Esteves et al. 2000, Ferreira et al. 2000). Também são comuns em planícies inundáveis do território brasileiro, como descrito por Granado-Lorencio et al. (2005) no rio Amazonas, Sato et al. (1987) no alto São Francisco e Petry et al. (2003) no alto rio Paraná.

Segundo Agostinho et al. (1993), é comum encontrar exemplares de Prochilotus lineatus em planícies alagadas do rio Paraná, onde permanecem até o amadurecimento das gônadas. Depois de jovem, 
saem para o rio principal quando as planícies se reconectam com o canal. Na lagoa Curralinho, porém, durante o estudo, só houve uma conexão com o rio, seguida do deplecionamento, levando a supor que os exemplares de espécies migradoras encontradas, inclusive outras, mesmo adultas, não tiveram chance de voltar ao rio e completar seu ciclo de vida.

Espécies reofílicas também não foram observadas por Smith \& Barrella (2000) na lagoa intermitentemente isolada do rio Sorocaba (SP). Os autores também associaram a diminuição da riqueza com as ações antrópicas ocorridas no local, como desmatamento e aterro.

Pompeu \& Alves (2003), analisando a extinção de peixes nativos na lagoa Santa, Minas Gerais, citam que a obstrução do canal de comunicação da lagoa, a introdução de espécies exóticas, as mudanças no nível da água, a poluição orgânica e a eliminação da vegetação marginal e submersa são as prováveis causas para a perda de espécies neste ambiente.

A exemplo do observado em Curralinho, os Characiformes encontrados em lagoas marginais são representados predominantemente por peixes de pequeno e médio porte, sedentários e nível trófico invertívoros. Populações de peixes de pequeno tamanho, com ciclo de vida curto, representadas principalmente por esta ordem, usualmente habitam as lagoas marginais, assim como tilápias e carás (Perciformes), associados ou não a macrófitas, que encontram nestes ambientes locais ideais para abrigo, alimentação e postura de ovos (Welcomme 1979, Smith \& Barrella 2000, Petry et al. 2003). Espécies sedentárias são comumente encontradas em áreas alagadas, desenvolvendo todo o ciclo de vida nestes ambientes, apresentando adaptações etológicas e fisiológicas às mudanças drásticas que ocorrem durante o período de seca (Nakatani et al. 1997).

Represamentos constituem uma importante fonte de impacto sobre as comunidades de peixes no trecho a jusante, atuando de forma diferenciada sobre espécies migradoras e residentes. Agostinho et al. (2007) mencionam que espécies sedentárias se reproduziram mais abundantemente em anos secos, enquanto as migradoras, nos anos de maiores cheias na planície de inundação do alto rio Paraná, a jusante da UHE Porto Primavera (PR). Sanches (2002) observou os efeitos sobre as larvas de peixes após o barramento deste reservatório, evidenciando um aumento de sua densidade e revelando uma desova bem sucedida, porém, com uma baixa captura de peixes no mesmo período. Tal fato pode ser explicado devido à falta de acesso das larvas aos ambientes alagáveis, em razão da ausência de conectividade desses ambientes com o canal principal (Agostinho et al. 2007).

Outra característica negativa do barramento de rios é a retenção de nutrientes no reservatório, tendendo ao empobrecimento do trecho a jusante, reduzindo a fertilidade das planícies alagáveis, afetando a sua biomassa faunística. Além disso, causa redução das áreas alagáveis e alteração nos habitats pela erosão, reduzindo o sucesso reprodutivo e diminuindo a produtividade pesqueira dos rios (Cunico et al. 2002, Agostinho et al. 2004a, Agostinho et al. 2005, Godinho et al. 2007).

A interferência nos pulsos de inundação pode causar uma dissincronia entre os períodos de cheia e os processos reprodutivos ou, mesmo que haja sincronia, a curta duração das cheias pode inviabilizar o desenvolvimento das formas jovens (Cunico et al. 2002). Os trabalhos realizados a jusante da represa Porto Primavera (alto rio Paraná) apontam uma alteração tanto nas espécies migradoras quanto não-migradoras, provavelmente, devido à redução de locais adequados de desova ou ao controle da inundação imposto pela usina, ocasionando um aumento da predação decorrente da elevada transparência da água (Sanches et al. 2006).

Para minimizar os efeitos das represas sobre a fauna local, têm sido propostas várias medidas de manejo, entre elas, o controle da descarga d'água como forma de manter um regime natural de cheias nas planícies de inundação do alto Paraná e reduzir os impactos sobre as assembléias de peixes (Agostinho et al. 2004b).

Após o enchimento do reservatório, os peixes tendem a habitar as zonas litorâneas, porém, a nova colonização só terá sucesso se estas espécies se adaptarem ao novo ambiente e conseguirem completar todo seu ciclo de vida neste ecossistema. Estas espécies são geralmente sedentárias, com ampla plasticidade alimentar (Agostinho et al. 2007), sendo menos dependentes da inundação (principalmente as que possuem cuidado parental) em comparação com as espécies migradoras, que desovam no trecho acima das planícies (Agostinho et al. 2004b).

Com base nas informações apresentadas neste trabalho, pode-se concluir, que a lagoa Curralinho é um importante ambiente de abrigo, alimentação e descanso para a ictiofauna, mantendo peixes forrageiros que servem de base para a cadeia trófica e a sustentação pesqueira. Uma avaliação de longo prazo sobre o comportamento da lagoa Curralinho e de sua ictiofauna em relação ao manejo da vazão pela usina de Sobradinho e sua conectividade com o rio São Francisco, é fundamental para a compreensão de seu papel na dinâmica reprodutiva e na estrutura populacional dos peixes deste trecho da bacia.

\section{Agradecimentos}

À Fundação Apolônio Salles de Desenvolvimento Educacional (FADURPE), pelo suporte logístico e pela viabilização financeira do projeto. Agradecemos à Divisão de Gestão de Recursos Hídricos (DGRH) da Companhia Hidro Elétrica do São Francisco (CHESF), pelos dados de vazão defluente do reservatório de Sobradinho.

\section{Referências Bibliográficas}

Agência de Desenvolvimento Agrário - ADAGRO. 2008. http://www.adagro. pe.gov.br/. (último acesso em 16/03/2008).

AGOSTINHO, A.A., VAZZOLER, A.E.E.M., GOMES, L.C. \& OKADA, E.K. 1993. Estratificación y comportamento de Prochilodus scrofa em distintas fases del ciclo de vida, en la planície de inundacón del alto rio Paraná y embalse de Itaipu, Paraná, Brasil. Rev. Hydrobiol. Trop. 26(1):79-90.

AGOSTINHO, A.A. \& ZALEWSKI, M. 1996. Planície alagável do alto rio Paraná: importância e preservação. EDUEM, Maringá, p. 100.

AGOSTINHO, A.A., THOMAZ, S.M. \& NAKATANI, K. 2001. A planície de inundação do alto Rio Paraná: aspectos físicos, biológicos e socioeconômicos. EDUEM, Maringá, p. 460.

AGOSTINHO, A.A., GOMES, L.C., SUZUKI, H.I. \& JÚLIO Jr., H.F. 2003. Migratory fishes of the Upper Parana River basin, Brazil. In Migratory fishes of South America: biology, fisheries and conservation status. (J. Carolsfeld, B. Harvey, C. Ross \& A. Baer, orgs.). 1 ed. World Fisheries Trust, Victoria, p. 19-99.

AGOSTinhO, A.A., THOMAZ, S.M. \& GOMES, L.C. 2004a. Threats for biodiversity in the floodplain of the Upper Paraná River: effects of hydrological regulation by dams. Ecohydrol. Hydrobiol. 4:255-268.

AGOSTINHO, A.A., GOMES, L.C., VERÍSSIMO, S. \& OKADA, E.K. 2004b. Flood regime, dam regulation and fish in the Upper Paraná river: effects on assemblage attributes, reproduction and recruitment. Rev. Fish Biol. Fisher. 14(1):11-19.

AGOSTINHO, A.A., THOMAZ, S.M. \& GOMES, L.C. 2005. Conservação da biodiversidade em águas continentais do Brasil. Megadiversidade. 1(1):70-78.

AGOSTINHO, A.A., GOMES, L.C. \& PELICICE, F.M. 2007. Ecologia e manejo de recursos pesqueiros em reservatórios do Brasil. EDUEM, Maringá, 502 p.

ARAÚJO-LIMA, C.A.R.M. \& OLIVEIRA, E.C. 1998. Transport of larval fish in the Amazon. J. Fish Biol. 53(A):297-306.

BAMBI, P. \& SILVA, V.P. 2000. Produção primária do fitoplâncton e as relações com as principais variáveis limnológicas da baía das Pedras, Pirizal, Pantanal, MT. In III Simpósio sobre recursos naturais e sócio- 
econômicos do Pantanal: os desafios do novo milênio. Corumbá - MS. Embrapa, Brasília, p. 114.

BOnETto, A.A., CORDiviola de YUAN, E., PIGNALBERI, C. \& OLIVEIROS, O. 1969. Ciclos hidrológicos del rio Paraná y las poblaciones de peces contenidas em las cuencas temporárias de su valle de inundación. Physis. 29(7/8):213-223.

BRITSKI, H.A., SATO, Y. \& ROSA, A.B.S. 1988. Manual de identificação de peixes da região de Três Marias: com chaves de identificação para os peixes da bacia do São Francisco. Câmara dos Deputados/Codevasf, Brasília, $11 \mathrm{p}$

BUCKUP, P.A., MENEZES, N.A. \& GHAZZI, M.S. 2007. Catálogo das espécies de peixes de água doce do Brasil. Museu Nacional, Rio de Janeiro, 195 p.

CARVALHO, E.D., MARCUS, L.R., FORESTI, E. \& SILVA, V.E.B. 2005. Fish assemblage attributes in a small oxbow lake (Upper Paraná river basin, São Paulo state, Brazil): species composition, diversity and ontogenetic stage. Acta Limnol. Bras. 17(1):45-56.

CASATTI, L. 2005. Fish assemblage structure in a first order stream, southeastern Brazil: longitudinal distribution, seasonality, and microhabitat diversity. Biota Neotrop. 5(1): http://www.biotaneotropica. org.br/v5n1/pt/abstract?article+BN02505012005 (último acesso em 30/11/2007).

CASATTI, L., LANGEANI, F. \& CASTRO, R.M.C. 2001. Peixes de riacho do Parque Estadual Morro do Diabo, Bacia do alto rio Paraná, SP. Biota Neotrop. 1(1):1-15.

CASTRO, R.J., FORESTI, F.E. \& CARVALHO, D. 2003. Composição e abundância da ictiofauna na zona litorânea de um tributário, na zona de sua desembocadura no reservatório de Jurumirim, Estado de São Paulo, Brasil. Acta Scient. Biol. Sci. 25(1):63-70.

CATELLA, A.C. 1992. Estrutura da comunidade e alimentação dos peixes da Baía do Onça, uma lagoa do Pantanal do rio Aquidauana, MG. Dissertação de Mestrado, Universidade Estadual de Campinas, Campinas, 215 p.

Companhia de Desenvolvimento do Vale do São Francisco - CODEVASF. 2008. http://www.codevasf.gov.br/osvales/vale-do-sao-francisco/recus/ submedio-sao-francisco. (último acesso em 07/04/2008)

Companhia de Desenvolvimento do Vale do São Francisco - CODEVASF. 2001. Almanaque Vale do São Francisco. Brasília, 412 p.

CUNICO, A.M., GRAÇA, W.J., VERÍSSIMO, S. \& MAURÍCIO, L. 2002. Influência do nível hidrológico sobre a assembléia de peixes em lagoa sazonalmente isolada da planície de inundação do alto Paraná. Acta Scient. Biol. Sci. 24(2):383-289.

DABÉS, M.B.G.S. 1995. Composição e descrição do zooplâncton de cinco lagoas marginais do rio São Francisco, Pirapora, Minas Gerais - Brasil. Rev. Brasil. Biol. 55(4):831-845.

DAJOZ, R. 2005. Princípios de ecologia. 7 ed. Artmed Editora, Porto Alegre, $520 \mathrm{p}$.

ESTEVES, F.A. 1998. Fundamentos de limnologia. 2 ed. Interciência, Rio de Janeiro, $575 \mathrm{p}$.

ESTEVES, K.E., SENDACZ, S., LOBO, A.V.P. \& XAVIER, M.B. 2000. Características físicas, químicas e biológicas de três lagoas marginais do rio Mogi-Guaçu (SP) e avaliação do seu papel como viveiro natural de espécies de peixes reofílicos. Bol. Inst. Pesca 26(2):169-179.

FERREIRA, A.G., VERANI, J.R., PERET, A.C. \& CASTRO, P.F. 2000. Caracterização da comunidade íctica de lagoas marginais do rio MogiGuaçu: composição, abundância e biomassa depeixes. In Estudos integrados em ecossistemas: estação ecológica de Jataí (J.E. Santos \& J.S.R. Pires, eds.). Rima Editora, São Carlos, p. 791-804. (v. 2).

GALETTI Jr., P.M., ESTEVES, K.E., LIMA, N.R.W., MESTRINER, C.A., CAVAllini, M.M., CESAR, A.C.G. \& MIYAZAWA, C.S. 1990. Aspectos comparativos da ictiofauna de duas lagoas marginais do rio Mogi-Guaçu (Alto Paraná -Estação de Jataí, SP). Acta Limnol. Brasil. 3:865-885.

GODINHO, A.L. \& GODINHO, H.P. 2003. Breve visão do São Francisco In Águas, peixes e pescadores do São Francisco das Minas Gerais
(H.P. Godinho \& A.L. Godinho, eds.). PUC Minas, Belo Horizonte, p. $15-25$.

GODINHO, A.L., KYNARD, B. \& MARTINEZ, C.B. 2007. Supplemental water releases for restoration in a Brazilian floodplain river: a conceptual model. River Res. Appl. 23(9):947-962.

GRANADO-LORENCIO, C., LIMA, R.M.A. \& LOBÓN-CERVIÁ, J. 2005. Abundance distribution relationships in fish assembly of the Amazonas floodplain lakes. Ecography. 28(4):515-520.

HALYC, L.C. \& BALON, E.K. 1983. Structure and ecological production of the fish taxocene of a small floodplain system. Can. J. Zool. 61(2):2446-2464.

JUNK, W.J. 1985. Temporary fat storage, an adaptation of some fish species to the waterlevel fluctuations and related environmental changes of the Amazon River. Amazoniana. 9:315-351.

JUNK, W.J., BAYLEY, P.B. \& SPARKS, R.E. 1989. The flood pulse concept in river-floodplain systems. Can. J. Fish. Aquat. Sci. 106:110-127.

LATINI, A.O. \& PETRERE Jr., M. 2004. Reduction of a native fish fauna by alien species: an example from Brazilian freshwater tropical lakes. Fisheries Manag. Ecol. 1(1):71-79.

LIMA, F.C.T., MALABARBA, L.R., BUCKUP, P.A., SILVA, J.F.P., VARI, R.P., HAROLD, A., BENINE, R., OYAKAWA, O.T., PAVANELLI, C.S., MENEZES, N.A., LUCENA, C.A.S., MALABARBA, M.C.S.L., LUCENA, Z.M.S., REIS, R.E., LANGEANI, F., CASATTI, L., BERTACO, V.A., MOREIRA, C. \& LUCINDA, P.H.F. 2003. Genera Incertae Sedis in Characidae. In Check list of the freshwater fishes of South and Central America. (R.E. Reis, S.O. Kullander \& C.J. Ferraris Jr., eds.). EDIPUCRS, Porto Alegre, p. 106-169.

LOUREIRO-CRIPPA, V.E. \& HAHN, N.S. 2006. Use of food resources by the fish fauna of a small reservoir (Rio Jordão, Brazil) before and shortly after its filling. Neotrop. Ichthyol. 4(3):357-362.

LOWE-MCCONNELL, R.H. 1987. Ecological studies in tropical fish communities. Cambridge University Press, London, 521 p.

LUDWIG, J.A. \& REYNOLDS, J.F. 1988. Statistical ecology: a primer on methods and computing. John Willey \& Sons, New York, 337 p.

LUZ, K.D.G., OLIVEIRA, E.F., PETRY, A.C., JÚLIO Jr., H.F., PAVANELLI, C.S. \& GOMES, L.C. 2004. Composição ictiofaunística da planície de inundação do alto rio Paraná. In A planície alagável do alto rio Paraná. (L. Rodrigues, A.A. Agostinho, S.M. Thomaz \& L.C. Gomes, eds.). EDUEM, Maringá, p. 101-106.

MARQUES, J.G.W. 1993. Etnoecologia, educação ambiental e superação da pobreza em áreas de manguezais. In Encontro nacional de educação ambiental em áreas de manguezais. Universidade Federal da Bahia, Maragogipe, p. 29-35.

MEDEIROS, E.S.F. \& MALTCHIK, L. 2001. Fish assemblage stability in an intermittently stream from the Brazilian semiarid region. Austral Ecol. 26(2):156-164.

MESCHIATTI, A.J., ARCIFA, M.S. \& FENERICH-VERANI, N. 2000. Ecology of fish in oxbow lakes of Mogi-Guaçu river. In Estudos integrados em ecossistemas. Estação Ecológica de Jataí. (J.E. Santos \& J.S.R. Pires, eds.). Rima Editora, São Carlos, p. 817-830.

MIRANDA, J.C. \& MAZZONI, R. 2003. Composição da ictiofauna de três riachos do alto Rio Tocantins - GO. Biota Neotrop. 3(1): http://www. biotaneotropica.org.br/v3n1/pt/abstract?article+BN00603012003 (último acesso em 20/01/2008).

MUNIZ, C.C. 2005. Composição da comunidade íctica em área limnética, relacionada ao ciclo hidrológico nas baías da Salobra e Negra, no Pantanal de Cáceres - MT. Dissertação de Mestrado, Universidade Federal de Mato Grosso, Cuiabá, 81 p.

NAKATANI, K., BAUMGARTNER, G., BIALETZKI, A. \& SANCHES, P.V. 1997. Ovos e larvas de peixes do reservatório do Segredo. In Reservatório de Segredo: bases ecológicas para o manejo (A.A. Agostinho \& L.C. Gomes, eds.). EDUEM, Maringá, p. 183-201.

NAKATANI, K., BIALETZKI, A., GALUCH, A.V., SANTIN, M., BORGES, R.Z., KIPPER, D., ZIOBER, S.R., BENEDETTO, M.L. \& ASSAKAWA, F. 2003. Monitoramento do ictioplâncton na planície de inundação do 
alto rio Paraná e utilização do rio Ivinheima (MS) como área de desova e criadouro natural de peixes. In A planície alagável do rio Paraná: estrutura e processos ambientais: componentes bióticos (A.A. Agostinho, S.M. Thomaz, L. Rodrigues \& L.C. Gomes, coords.). Programa PELD/CNPq, Maringá, 56 p. (Relatório/2003).

NUNES, Z.M.P. 2000. Interações entre peixes onívoros: proposta de um policultivo para pequenos açudes do semiárido nordestino. Tese de Doutorado, Universidade Federal de São Carlos, São Carlos, 280 p.

PAIVA, M.P., PETRERE Jr., M., PETENATE, A.J., NEPOMUCENO, F.H. \& VASCONCELOS, E.A. 1994. Relationship between the number of predatory fish species and fish yield in large North-eastern Brasilian reservoirs. In Rehabilitation of freshwater fisheries. (I.G. Cowx, ed.). Fishing News Books, London, p. 120-129.

PETRERE Jr., M. 1983. Relationships among catches, fishing effort and river morphology for eight rivers in Amazonas State (Brazil), during 1976-1978. Amazoniana. 8(2):281-296.

PETRY, A.C., AGOSTINHO, A.A. \& GOMES, L.C. 2003. Fish assemblages of tropical floodplain lagoons: exploring the role of connectivity in a dry year. Neotrop. Ichthyol. 1(2):111-119.

PETRY, A.C., ABUJANRA, F., PIANA, P., JÚLIO Jr., H.F. \& AGOSTINHO, A.A. 2004. Fish assemblages of the seasonally isolated lagoons of the Upper Paraná River Floodplain. In Structure and functioning of the Paraná River and its Floodplain. (A.A. Agostinho, L. Rodrigues, L.C. Gomes, S.M. Thomaz \& L.E. Miranda, orgs.). EDUEM, Maringá, p. 131-137.

PIELOU, E.C. 1966. The measurement of diversity in different types of biological collections. J. Theor. Biol. 13(2):131-144.

POMPEU, P.S. 1997. Efeitos das estações seca e chuvosa e da ausência de cheias nas comunidades de peixes de três lagoas marginais do médio São Francisco. 1997. Dissertação de Mestrado, Universidade Federal de Minas Gerais, Belo Horizonte, 72 p.

POMPEU, P.S. \& ALVES, C.B.M. 2003. Local fish extinction in a small tropical lake in Brazil. Neotrop. Ichthyol. 1(2):133-135.

POMPEU, P.S. \& GODINHO, H.P. 2003. Ictiofauna de três lagoas marginais do médio São Francisco. In Águas, peixes e pescadores do São Francisco das Minas Gerais (H.P. Godinho \& A.L. Godinho, orgs.). PUC Minas Gerais, Belo Horizonte, p. 167-181.

POMPEU, P.S. \& GODINHO, H.P. 2006. Effects of extended absence of flooding on the fish assemblages of three floodplain lagoons in the middle São Francisco River, Brazil. Neotrop. Ichthyol. 4(4):427-433.

REIS, R.E., KULLANDER, S.O. \& FERRARIS Jr., C.J. 2003. Check list of the freshwater fishes of South and Central America. EDIPUCRS, Porto Alegre, $729 \mathrm{p}$.

RODRÍGUEZ, M.A. \& LEWIS, W.M. 1994. Regulation and stability in fish assemblages of Neotropical floodplain lakes. Oecologia. 99(1-2):166-180.

ROSA, R.S., MENEZES, N.A., BRITSKI, H.A., COSTA, W.J.E.M. \& GROTH, F. 2003. Diversidade, padrões de distribuição e conservação dos peixes da Caatinga. In Ecologia e conservação da Caatinga. (I.R. Leal, M. Tabarelli \& J.M.C. Silva, eds.). Universidade Federal de Pernambuco, Recife, p. 135-180.

SAMPAIO, E.V. \& LÓPEZ, C.M. 2000. Zooplankton community composition and some limnological aspects of an oxbow lake of the Paraopeba River, São Francisco River Basin, Minas Gerais, Brazil. Braz. Arch. Biol. Techn. 43(3):285-293.

SAMPAIO, E.V. \& LÓPEZ, C.M. 2003. Limnologia física, química e biológica da represa de Três Marias e do São Francisco. In Águas, peixes e pescadores do São Francisco das Minas Gerais (H.P. Godinho \& A.L. Godinho, orgs.). PUC Minas Gerais, Belo Horizonte, p. 71-92.

SANCHES, P.V. 2002. Influências do nível e canais sobre a deriva e alterações causadas pelo barramento sobre o ictioplâncton na região da planície de inundação do alto rio Paraná, Brasil. Tese de Doutorado, Universidade Estadual de Maringá, Maringá, 47 p.

SANCHES, P.V., NAKATANI, K., BIALETZKI, A., BAUMGARTNER, G., GOMES, L.C. \& LUIZ, E.A. 2006. Flow regulation by dams affecting ichthyoplankton: the case of the Porto Primavera dam, Paraná river, Brazil. River Res. Appl. 22:555-565.
SANT'ANNA, J.F.M., ALMEIDA, M.C., VICARI, M.R. SHIBATTA, O.A. \& ARTONI, R.F. 2006. Levantamento rápido de peixes em uma lagoa marginal do rio Imbituva na bacia do alto Rio Tibagi, Paraná, Brasil. Biol. Saúde. 12(1):39-46.

SATO, Y. \& GODINHO, H.P. 1999. Peixes da bacia do rio São Francisco. In Estudos ecológicos de comunidades de peixes tropicais. (R.H. LoweMcConnell, ed.). EDUSP, São Paulo, p. 401-413.

SATO, Y., BAZZOLI, N., RIZZO, E., BOSCHI, M.B. \& MIRANDA, M.O.T. 2003. Impacto a jusante do reservatório de Três Marias sobre a reprodução do peixe reofílico curimatá-pacu (Prochilodus argenteus). In Águas, peixes e pescadores do São Francisco das Minas Gerais (H.P. Godinho \& A.L. Godinho, orgs.). PUC Minas Gerais, Belo Horizonte, p. 327-345.

SATO, Y., CARDOSO, E.L. \& AMORIM, J.C.C. 1987. Peixes das lagoas marginais do São Francisco a montante da represa de Três Marias (Minas Gerais). CODEVASF, Brasília, 42 p.

SATO, Y. \& SAMPAIO, E.V. 2005, A ictiofauna na região do alto São Francisco, com ênfase no reservatório de Três Marias, Minas Gerais. In Ecologia de reservatórios: impactos potenciais, ações de manejo e sistemas em cascata. (M.G. Nogueira, R. Henry \& A. Jorcin, orgs.). Rima Editora, São Carlos, p. 251-304.

SILVA, C.J. \& ESTEVES, F.A. 1995. Dinâmica das características limnológicas das baías Porto de Fora e Acorizal em função da variação do nível da água (Pantanal de Mato Grosso). Oecologia Brasilensis I: estrutura, funcionamento e manejo de ecossistemas brasileiros. Instituto de Biologia, Universidade Federal do Rio de Janeiro, Rio de Janeiro, p. $47-60$

SIMABUKU, M.A.M. 2005. Ecologia de peixes que ocupam diferentes habitats da planície de inundação do rio Mogi-Guaçu, SP. Tese de Doutorado, Universidade Federal de São Carlos, São Carlos, 115 p.

SMITH, W.S. \& BARRELLA, W. 2000. The ichthyofauna of the marginal lagoons of the Sorocaba River, SP, Brazil: composition, abundance and effect of the anthropogenic actions. Rev. Bras. Biol. 60(4):627-632.

SÚAREZ, Y.R., PETRERE Jr., M. \& CATELLA, A.C. 2004. Factors regulating diversity and abundance of fish communities in Pantanal lagoons, Brazil. Fisheries Manag. Ecol. 11:45-50.

TEIXEIRA, T.P., PINTO, B.C.T., TERRA, B.F., ESTILIANO, E.O., GRACIA, D. \& ARAÚJO, F.G. 2005. Diversidade das assembléias de quatro unidades geográficas do rio Paraíba do Sul. Iheringia Ser. Zool. 95(4):347-357.

THOMAS, S.M., ROBERTO, M.C. \& BINI, L.M. 1997. Caracterização limnológica dos ambientes aquáticos e influência dos níveis fluviais. In A planície de inundação do alto rio Paraná: aspectos físicos, biológicos e socioeconômicos (A.E.A.M. Vazzoller, A.A. Agostinho, N.S.A. Hahn, eds.). EDUEM, Maringá, p. 73-102.

VAZZOLER, A.E.A.M., LIZAMA, M.A.P. \& INADA, P. 1997. Influências ambientais sobre a sazonalidade reprodutiva. In A planície de inundação do alto rio Paraná: aspectos físicos, biológicos e socioeconômicos (A.E.A.M. Vazzoler, A.A. Agostinho \& N.S. Hahn, eds.). EDUEM, Maringá, p. 267-280.

VERÍSSIMO, S. 1994. Variação na composição da ictiofauna em três lagoas sazonalmente isoladas, na planície do alto rio Paraná, Ilha Porto Rico, PR, Brasil. Dissertação de Mestrado, Universidade Federal de São Carlos, São Carlos, 77 p.

WELCOMME, R.L. 1979. Fisheries ecology of floodplain rivers. Longman, London, $317 \mathrm{p}$.

WINEMILLER, K.O. 1989. Patterns of variation in life history among South American fishes in seasonal environments. Oecologia. 81:225-241.

ZAR, J.H. 1996. Biostatistical analysis. 3 ed. Prentice-Hall, London, 662 p.

ZEUG, S.C., WINEMILLER, K.O. \& TARIM, S. 2005. Response of river Oxbow fish assemblage to patterns of hidrologic connectivity and environmental variability. T. Am. Fish. Soc. 134(5):1389-1399.

Recebido em 08/12/08

Versão Reformulada recebida em 29/05/09

Publicado em 28/07/09 